\title{
Dos textos astrológicos conservados en el comentario al Sefer Yeșirá de Yehudá ben Barzilay al-Bargeloní
}

\author{
Shlomo Sela * \\ Bar Ilan University
}

\begin{abstract}
Este artículo tiene como principal propósito traducir, estudiar los contenidos y descubrir las fuentes de dos textos astrológicos hebreos conservados en el comentario al Sefer Yeșirá de Yehudá ben Barzilay, la principal autoridad rabínica de Barcelona en las primeras décadas del siglo XII. El primer texto despierta gran interés porque incorpora el primer horóscopo documentado escrito en lengua hebrea conocido. El segundo texto incorpora una miscelánea de teorías cosmológicas y astrológicas. El análisis de ambos fragmentos revela un caso especial de recepción de fuentes astrológicas y científicas por intelectuales judíos en la península Ibérica. En claro contraste con Abraham bar Hiiyya y Abraham Ibn 'Ezra, que encarnan una corriente renovadora orientada a verter al hebreo diversos aspectos de la astrología y ciencia griega y árabe, Yehudá ben Barzilay representa una modalidad conservadora inclinada a la utilización de fuentes astrológicas y científicas de autores exclusivamente judíos.
\end{abstract}

PaLABRAS ClAVE: astrología hebrea; cosmología hebrea; transmisión de textos astrológicos; comentarios a Sefer Yeșirá; Baraita di-Šemuel; Baraita de-Mazzalot.

Two Astrological Fragments Included in the Commentary to Sefer Yeșirah by Yehudah ben BARZILAY AL-BARGELONI.-The main object of this article is to translate, scrutinize the contents and reveal the sources of two Hebrew astrological texts embedded in the commentary on Sefer Yeșirah composed by Yehudah ben Barzilay, the leading Rabbinic authority in Barcelona in the first half of the $12^{\text {th }}$ century. The first text arises great interest because it incorporates the first ever known horoscopic chart written in Hebrew. The second text includes a miscellany of cosmological and astrological theories. The analysis of both fragments reveals the reception of astrological texts by Jewish intellectuals in the Iberian Peninsula. In contrast with Abraham bar Hiyya and Abraham Ibn 'Ezra, who epitomize a renovating trend couching into a Hebrew mold various aspects of Greek and Arabic science, Ben Barzilay embodies a conservative trend which exclusively relies on Jewish astrological and scientific sources.

KeYwords: Hebrew Astrology; Hebrew Cosmology; Transmission of Astrological Texts; Commentaries to Sefer Yeșirah; Baraita di-Shmuel; Baraita de-Mazzalot.

La imponente estatura científica de Abraham bar Hiyya (ca. 1065-ca.1140) y Abraham Ibn 'Ezra (ca. 1087-ca. 1167) ha relegado a la oscuridad la contribución de otros autores hispanojudíos del siglo XII, como Yehudá ben Barzilay al-Bargeloní, la principal autoridad rabínica de Barcelona en las primeras décadas de ese siglo.

\footnotetext{
*shlomo@mail.biu.ac.il
} 
Aunque mucho más modesta en comparación con la monumental obra de Bar Hiiyya e Ibn 'Ezra, la importancia de la aportación de Yehudá ben Barzilay en el campo de las ciencias reside en un hecho fundamental: fue realizada en lengua hebrea y es posiblemente la primera manifestación, o una de las primeras manifestaciones, de este tipo en la península Ibérica, recogiendo tradiciones científicas vertidas previamente en hebreo y en otras lenguas. Este artículo tiene como propósito examinar dos textos astrológicos conservados en el comentario al Sefer Yeșirá de Yehudá ben Barzilay, traducirlos y estudiar minuciosamente sus contenidos, haciendo hincapié en la dilucidación de las fuentes astrológicas e históricas. La importancia del primer texto, según veremos, reside en que representa uno de los primeros intentos de crear una terminología astrológica hebrea destinada a describir los componentes del horóscopo, y la relevancia del segundo consiste en que recoge material astrológico conservado en antiguas baraitot y nos ayuda a descifrar su historia.

El principal dato biográfico que tenemos acerca de Yehudá ben Barzilay es la noticia del envío por Abraham bar Hiyya de una epístola en defensa de la astrología ${ }^{1}$. De ello deducimos que nació a finales del siglo XI, y que vivió durante las primeras décadas del siglo XII en Barcelona, la misma ciudad en la cual residía Bar Hiyya. Su apodo Al-Bargeloní no sólo nos indica que residió, sino también que muy posiblemente nació en Barcelona. Además, el título que ostentaba, Ha-Nasí, el príncipe, permite suponer que perteneció a una familia destacada de esa ciudad. Su posición de principal autoridad rabínica y halájica en Barcelona queda evidenciada no sólo por las múltiples citas a su nombre en colecciones de responsa, sino especialmente por su obra literaria, dedicada casi exclusivamente a la codificación halájica, sirviendo posteriormente sus libros

1 Ed. Z. Schwarz, «Abraham bar Ḥiyya, Iggeret R. Abraham b. Hiyya ha-Nasi še-katab le-R. Yehudá b. R. Barzilay 'al šeelá be-kaldaim», en S. KRAus (ed.), Festschrift Adolf Schwarz, zum siebzigsten Geburstag (Berlin-Wien 1917), págs. 23-36. En las primeras décadas del siglo XII, Bar Hiyya aplicó la astrología para elegir la hora en la que debería celebrarse el casamiento de uno de sus alumnos. Uno de los invitados se opuso argumentando que esto equivaldría a «preguntar a los Caldeos», lo cual está vedado en el Talmud (Pes 113b). Sintiéndose «un trasgresor y un pecador», Bar Hiyya envió a Yehudá ben Barzilay una epístola en la cual estudiaba las bases halájicas de esa prohibición y defendía un cierto tipo de astrología que consideraba totalmente armónico con el judaísmo. Varios investigadores modernos han identificado a Yehudá ben Barzilay con el detractor que acusó a Bar Hiyya en el casamiento, y por consiguiente lo han considerado un oponente de la astrología. Ver, inter alia, S. BARON, A Social and Religious History of the Jews, vol. VI (New York 1958), pág. 149; C. Sirat, A History of Jewish Philosophy in the Middle Ages (Cambridge 1990), págs. 94-95; M. ORFALI, Biblioteca de autores lógicos hispano-judios (Siglos XI-XV) (Granada 1997), pág. 50. Sin embargo, serias razones ponen en duda esta posibilidad. Para un análisis de esas razones y de la epístola, ver Sh. SELA, «Abraham Bar Hiyya’s Astrological Work and Thought», JSQ 12 (2006), págs. 128-158. 
como modelo a los codificadores provenzales y centroeuropeos ${ }^{2}$. Estos escuetos detalles biográficos apenas nos dejan intuir alguna afinidad entre el personaje central de este artículo y las ciencias. Pero Yehudá ben Barzilay insertó, según veremos, importantes contenidos científicos en su voluminoso comentario al Sefer Yeșirá ('Libro de la Creación'), del cual nos ocupamos a continuación.

Numerosas obras fueron escritas desde el siglo X hasta la Edad Moderna para explicar los arcanos contenidos del Sefer Yeșirá (de aquí en adelante SY), la más temprana obra hebrea dedicada al pensamiento cosmológico y cosmogónico ${ }^{3}$. Pero aquí conviene examinar brevemente la primera ola de comentarios, ya que es en esta tradición literaria donde se inserta el comentario a $S Y$ de Yehudá ben Barzilay (de aquí en adelante $C S Y$ ) ${ }^{4}$. El primer comentario del cual tenemos conocimiento fue escrito en lengua árabe aproximadamente en el año 931 en Bagdad por Sa'adyá Gaón ${ }^{5}$. Aproximadamente veinte años más tarde compuso un segundo comentario en árabe Dunaš Ibn Tamin, alumno de Isaac Israilí, médico, astrónomo y gramático judío de Kairuán, que se empeñó en su propio comentario en corregir los errores de Sa'adyá Gaón ${ }^{6}$. Paralelamente, Šabbetai

${ }^{2}$ En este campo, Yehudá ben Barzilay compuso las siguientes obras: Sefer ha- Itțim ('Libro de los tiempos'), que estudia las normas referentes al sábado y a las fiestas del calendario judío; Sefer ha-Dinim ('Libro de las leyes'), sobre el derecho civil; Sefer ha-Šetarot ('Libro de los formularios'), sobre letras de cambio y derecho mercantil; Yiḥus Šeer Basar ('Linajes y herencias'). Para la vida y obra de Yehudá ben Barzilay, véase OrfaLi, Biblioteca de autores lógicos hispano-judíos, págs. 50-52; I. M. TA-SHMA, «Judah Ben Barzillai ("ha-Nasi”) Al-Bargeloni», Encyclopaedia Judaica [= EJ] X (Jerusalem 1971), cols. 341-342. Y también G. VAJDA, «Le système des sciences exposé par Abraham bar Hiiyya et une page de Juda ben Barzilaï», Sef 22 (1962), págs. 60-68.

3 Sefer Yeșirá explica la creación del mundo por medio de «32 secretos senderos de sabiduría»: «10 sefirot belimá» y «22 letras elementales», que son las letras del alfabeto hebreo. Para una breve, pero excelente noticia bibliográfica de esta obra, ver G. ScHoLEM, «Sefer Yezirah», EJ XVI (Jerusalem 1971), cols. 782-788.

${ }^{4}$ R. Jospe, «Early Philosophical Commentaries on the Sefer Yezirah: Some Comments», RÉJ CXLIX (1990), págs. 369-415; SCHOLEM, «Sefer Yezirah», cols. 786-787; J. DAN, On Sanctity: Religion, Ethics and Mysticism in Judaism and other Religions (hebreo; Jerusalem 1998), págs. 234-242.

5 Para el original árabe, acompañado de una traducción hebrea, véase: Y. QAFIH (ed.), Sefer Yeșirá (Kitâb al-Mabâdi), 'im Perušha-Gaón Rabbenu Sa 'adyáb. R. Yosef Hajjumîz. l. (Jerusalem 1972) (en adelante, Kitâb al-Mabâdi). Para una traducción francesa, véase Commentaire sur le Sefer Yesira ou Livre de la création, par le Gaon Saadja de Fayyoum, publié et traduit par M. LAMBERT (Paris 1891).

${ }^{6}$ G. VAJDA, Le Commentaire sur le Livre de la Création de Dûnaš ben Tâmîm de Kairouan ( $X^{e}$ siècle). Nouvelle édition revue et augmentée par Paul B. Fenton (Paris-Louvain 2002). Para una traducción hebrea, ver Sefer Yeșirá 'im Peruš Abusaḥl Dunaš ben Tamim, ed. M. GrossberG (London 1902; reimpr. 1970). 
Donnolo, médico, farmacólogo y astrónomo, componía en el sur de Italia el primer comentario hebreo al SY, titulado Sefer Hakmoni ${ }^{7}$.

A partir de fines del siglo XI, el centro de gravedad pasa a la península Ibérica. Notamos un primer indicio en la poesía de Šelomó Ibn Gabirol (ca. 1022-ca. 1058) ${ }^{8}$. También en Al-Andalus, continuando la tradición de los comentarios escritos en la lengua árabe, el poeta, filósofo y médico Yehudá ha-Leví (ca. 1075-ca. 1141) dedicaba un capítulo importante del Cuzarí a comentar el $S Y^{9}$. Ya en la primera mitad del siglo XII componía Yehudá ben Barzilay un cuarto comentario al $S Y$, el más voluminoso y completo entre los cuatro primeros comentarios. $C S Y$ fue publicado en 1885 por S. J. Halberstam basándose en un único manuscrito ${ }^{10}$. En contraste con los comentarios de Sa'adyá Gaón, Dunaš Ibn Tamim y Yehudá haLeví, CSY fue escrito en hebreo y esa elección obedecía a una nueva demanda de literatura escrita en lengua hebrea en la península Ibérica ${ }^{11}$. Una característica fundamental de Sa'adyá Gaón, Dunaš Ibn Tamim, Šabbetai Donnolo, Yehudá ha-Leví y Yehudá ben Barzilay es que vieron en el $S Y$ una obra científica, y por lo tanto otorgaron a ciertas partes de sus comentarios un carácter netamente científico y filosófico ${ }^{12}$. Por consiguiente, no nos debe asombrar que el CSY incluya pasajes centrados en la astronomía, matemáticas, astrología, medicina, biología y cosmología. El estudio de todos estos textos rebasa los límites de este artículo, y sería apropiado analizarlos detalladamente en otra ocasión.

En este artículo me limito a estudiar en detalle dos textos astrológicos conservados en el CSY. El tratamiento de cada uno de ellos está dividido en

7 D. Castelli (ed.), Il commento de Sabbetai Donnolo sul libro della creazione (Firenze 1880).

8 SCHolem, «Sefer Yezirah», col. 787.

9 Yehudá ha-Leví, Sefer ha-Kuzarí (hebreo), ed. and transl. Yehudah Iвn Shmuel (Tel Aviv 1972), IV:25, págs. 179-188.

${ }^{10}$ S. J. Halberstam, Commentar zum Sepher Jezira von R. Jehuda b. Barsilai aus Barcelona (Berlin 1885) (de aquí en adelante, Commentar).

11 Abraham Ibn 'Ezra continúa esta tradición al referirse en varias partes de su obra, tanto exegética como científica, al $S Y$. Más aún, de acuerdo a una tradición divulgada en la península Ibérica a partir del siglo XIII por Abraham Abulafia, autor de un comentario al SY, Abraham Ibn 'Ezra había compuesto un comentario al $S Y$. Ningún comentario de Ibn 'Ezra al $S Y$ ha sido hallado hasta este momento, aunque los supercomentarios hispanojudíos de Ibn 'Ezra en el siglo XIV continuaron aferrándose a esta tradición, citando literalmente algunos fragmentos del supuesto comentario de Ibn 'Ezra al SY. Acerca del comentario de Ibn 'Ezra, ver P. Fenton, « R. Abraham ibn Ezra et le Commentaire kairouanais sur le Sefer Yeșînâh », en VAJDA, Le Commentaire sur le Livre de la Création, págs. 159-175.

12 Y. DAN, «Peruš Sefer Yeșirá le-R. Yehudá ben Barzilay ha-Bargeloní», Mašuot (1994), 99-119, especialmente págs. 99-104. 
tres partes. En primer lugar, la edición del texto hebreo que no sigue servilmente la edición de S. J. Halberstam y la coteja con el texto del único manuscrito ${ }^{13}$. En la mayoría de los casos he podido corregir errores basándome en las fuentes que utilizó Yehudá ben Barzilay para estos dos textos. Las diversas fuentes son señaladas en las notas con letras hebras, siendo la letra reservada para el manuscrito y la letra $n$ para la edición de S. J. Halberstam. En segundo lugar, la traducción al español. Tanto los textos hebreos como las correspondientes traducciones han sido divididos en pasajes numerados en forma ascendente para facilitar la referencia a las partes internas de los dos fragmentos. En tercer lugar, un comentario centrado en la dilucidación de los contenidos astrológicos y la revelación de las fuentes astrológicas e históricas.

I. LA CONFIGURACión DE LA ESFERA: MEDIODÍA DEL 12 DE SIVÁN DE 1242 (ERA SELEÚCIDA)

\section{TEXTO HEBREO}

מ = Ms. London, Montefiore Library 312, fol. 129a (Institute for Microfilmed Hebrew Manuscripts, Jewish National and University Library, F 05257).

ה = S. J. Halberstam, Commentar sum Sepher Jezira von R. Jehuda b. Barsilai aus Barcelona (Berlin 1885), pág. 214.

$p=$ Yosef Qafih (ed.), Sefer Yeșirá (Kitâb al-Mabâdi), 'im Peruš ha-Gaon Rabbenu Sa 'adyá b. R. Yosef Hajjumî z.l. (Jerusalem 1972), págs. 86-87.

(1) ומבואר מזה למי יראה מעשה הקפת הגלגל כי היא הקפתו כמו גלגל מזל מן המזלות,

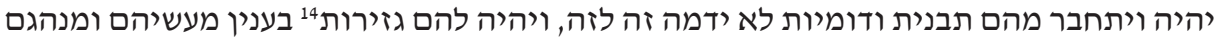

באותו ענין. - ביתות

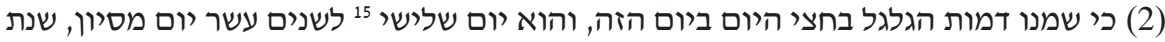

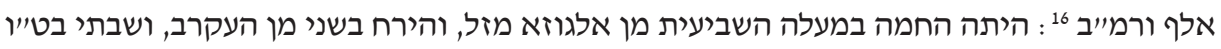

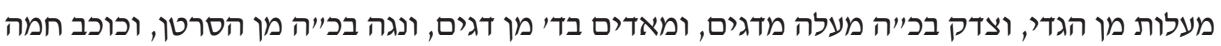

\footnotetext{
13 Ms. London, Montefiore Library 312, fols. 1-168.

14 גזירות]; corregido según el contexto.

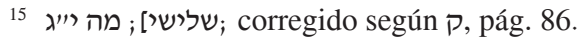

16 ק ק pág. pá. 86.

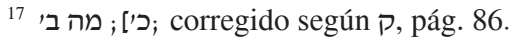




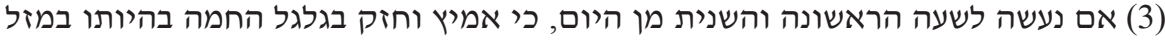

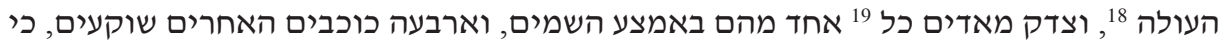

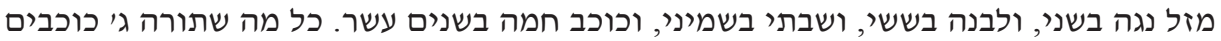

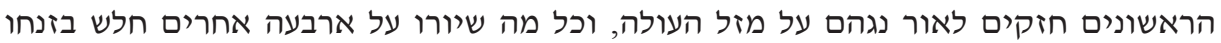

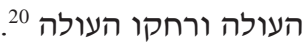

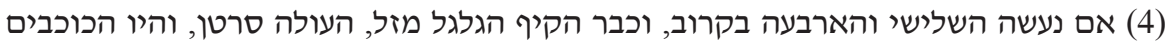

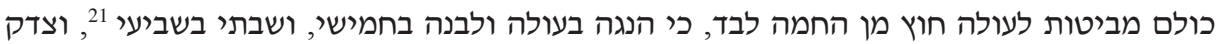

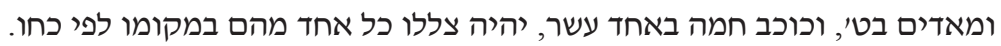

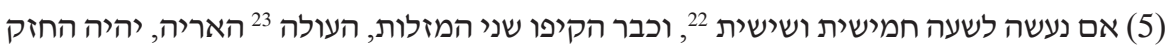

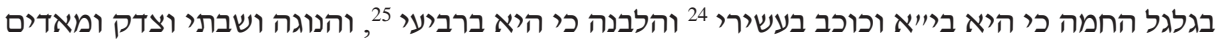
הם כולם שוקעים, וכנגד זה הענין יהיה כל מה בתי שתורה עליר עליו.

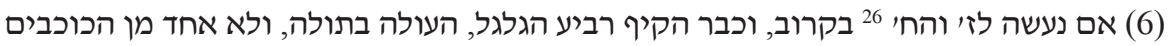

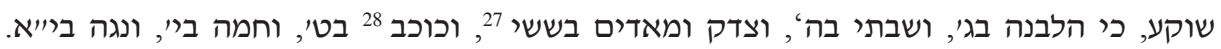
ויתבאר כל ההוראות מאלו העניינים.

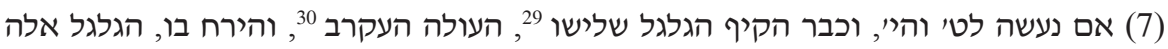
האחרים בהפך מה שזכרנו, וכן משנים בשני שעות האחרות ומאחריה השיהן תוכן הקפתו.

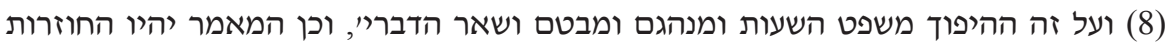

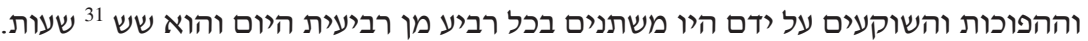

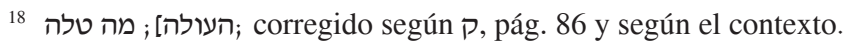

19 כלי; completado según el contexto.

20 corregido según el contexto.

21 ק, pág. 87.

22 ק קושישית]; pág. corregido segú 87 y según el contexto.

23 בהעולה]; corregido según el contexto.

24 ק ק p corregido segúg. 87 y según el contexto.

25 ;הלבנה כי היא ברביעי]; מה והלבנה בו׳ כי הוא ברביעי; corregido según el contexto.

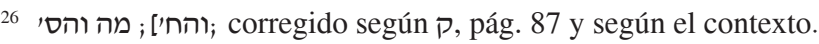

27 קדק וצדים; corregido segúg. 87 y según el contexto.

28 ק ק pág. pán y según el contexto.

29 ק ק קלישו]; pág. 87 y según el contexto.

30 ing corregido según el contexto.

31 קשe; corregido según pág. 87 y según el contexto.
} 


\section{TRADUCCIÓN}

(1) Queda claro para quien observa la revolución de la esfera que cuando gira <el intervalo de $>$ un signo de los signos zodiacales se forman configuraciones ${ }^{32}$ disímiles las unas de las otras, y de ellas derivan los juicios <astrológicos> que están basados en sus correspondientes acciones rutinarias.

(2) Calculamos la configuración de la esfera al mediodía del día de hoy, tercer día $<$ de la semana>, doce del mes de siván del año $1242^{33}$ : Sol: Géminis $7^{\circ}$; Luna: Escorpio $2^{\circ}$; Saturno: Capricornio $15^{\circ}$; Júpiter: Piscis $25^{\circ}$; Marte: Piscis $4^{\circ}$; Venus: Cancer $25^{\circ}$; Mercurio: Tauro $20^{\circ}$.

(3) Si calculamos <esta misma configuración> para la primera y segunda hora del día ${ }^{34}$, el <planeta> regente en la esfera es el Sol porque está en el signo zodiacal ascendente, luego Júpiter y Marte cada uno de ellos está en el medium coelum ${ }^{35}$, los cuatro planetas restantes se hunden ${ }^{36}$, porque Venus está en la segunda <casa horoscópica>, la Luna en la sexta, Saturno en la octava y Mercurio en la duodécima. Las indicaciones de los tres primeros ${ }^{37}$ son poderosas porque la luz de sus rayos cae en el signo ascendente ${ }^{38}$, y todo lo que indican los cuatro restantes ${ }^{39}$ es débil porque su luz se ausenta y se aleja del ascendente ${ }^{40}$.

(4) Si calculamos <esta misma configuración $>$ para la tercera y cuarta <hora del día $>$ aproximadamente, la esfera $<$ celeste $>$ ha girado $<$ el intervalo de $>$ un signo zodiacal, Cáncer es el ascendente, todos los planetas están en aspecto con el ascendente excepto el Sol, ya que Venus está en el ascendente, la Luna en la quinta <casa horoscópica>, Saturno en la séptima, Júpiter y Marte en la novena, y Mercurio en la undécima, y la indicación de cada uno de ellos en su posición es según su fuerza.

(5) Si calculamos < esta misma configuración $>$ para la quinta y sexta $<$ hora del día, $\mathrm{y}<\mathrm{la}$ esfera $>$ ya ha girado $<$ el intervalo de $>$ dos signos zodiacales, el ascendente es Leo,

${ }^{32}$ O sea, diagramas horoscópicos.

${ }^{33}$ Miércoles, 31 de mayo de 931.

${ }^{34}$ Contando desde el amanecer.

35 El medium coelum, medio cielo, es la intersección entre el meridiano que pasa sobre la cabeza del observador y el zodíaco. Señala el comienzo de la décima casa astrológica y es uno de los puntos de referencia más importantes del horóscopo.

${ }^{36} \mathrm{O}$ sea, no están en aspecto con el ascendente.

37 Sol, Júpiter, Marte.

${ }^{38}$ El Sol está en el ascendente; Júpiter y Marte están en aspecto de cuadratura con el ascendente.

39 Venus, Luna, Saturno, Mercurio.

${ }^{40}$ No están en ningún aspecto con respecto al ascendente. 
el $<$ planeta $>$ regente en la esfera es el Sol que está en la undécima <casa horoscópica $>$ y $<$ también $>$ Mercurio que está en la décima y <también $>$ la Luna que está en la sexta; Venus y Saturno y Júpiter y Marte todos ellos se hunden, ${ }^{41}$ y todo lo que indican es con respecto a esto.

(6) Si calculamos <esta misma configuración > para la séptima y octava <hora del día $>$ aproximadamente, y ya ha girado <el intervalo de $>$ un cuarto de la esfera, el ascendente es Virgo, y ninguno de los planetas se hunde, porque la Luna está en la tercera $<$ casa horoscópica $>$, Saturno en la quinta, Júpiter y Marte en la sexta, Mercurio en la novena, el Sol en la décima y Venus en la undécima. Y todas las indicaciones derivan de estas posiciones.

(7) Si calculamos <esta misma configuración> para la novena y décima <hora del día $>$, y ya ha girado <el intervalo de $>$ un tercio de la esfera, el ascendente es Escorpio, la Luna esta allí ${ }^{42}$, la esfera y los demás $<$ planetas $>$ están en forma opuesta a lo que ya hemos mencionado, y análogamente cambian en las dos horas siguientes y después de ellas también con respecto a la configuración de la rotación.

(8) La regla de las horas y sus acciones rutinarias, sus aspectos y los demás asuntos $<$ derivan $>$ de esta variación, y también la doctrina de los < signos $>$ fijos, variables y tropicales, ${ }^{43} \mathrm{y}$ de ellos derivan cambios cada cuarto del día, que corresponden a seis horas.

\section{COMENTARIO}

Este texto es una traducción palabra por palabra del árabe al hebreo de un fragmento del Tafsîr Kitâb al-Mabâdi, el comentario escrito por Sa'adyá Gaón al $S Y^{44}$. La curiosa fecha de «la configuración de la esfera» registrado tanto en nuestro texto (\$2) como en el Tafsîr Kitâb al-Mabâdi — mediodía del tercer día de la semana, doce del mes de siván del año de 1242 de la era seleúcida- corresponde al miércoles, 31 de mayo de 931 de la era cristiana y es, en realidad, la fecha de composición del comentario escrito por Sa'adyá Gaón ${ }^{45}$. Numerosos son los lugares donde Yehudá ben Barzilay declara explícitamente que está introduciendo en su propio comentario fragmentos de la obra de Sa'adyá Gaón.

41 No están en ningún aspecto con respecto al ascendente.

42 En Escorpio.

43 Los signos fijos son Aries, Cáncer, Libra y Capricornio; los variables son Tauro, Leo, Escorpio y Acuario; los tropicales son Géminis, Virgo, Sagitario y Piscis. Los nombre derivan del clima especial que reina cuando el Sol cruza estos signos durante su marcha anual.

44 Kitâb al-Mabâdi, pág. 86. El fragmento correspondiente de Sa'adyá Gaón ha sido traducido al inglés y estudiado por B. R. Goldstein, «Astronomy and the Jewish Community in Early Islam», Aleph 1 (2001), págs. 50-54.

45 Goldstein, «Astronomy and the Jewish Community», págs. 39-40. 
En la gran mayoría de los casos se trata de pasajes del Tafsîr Kitâb al-Mabâdi ${ }^{46}$, pero en otros utiliza también el comentario de Sa'adyá Gaón a Génesis ${ }^{47}$.

La traducción del fragmento del Tafsîr Kitâb al-Mabâdi que Yehudá ben Barzilay integró en el $C S Y$ despierta gran interés porque representa el primer horóscopo escrito en la lengua hebrea del cual tenemos conocimiento hasta el presente. También en la historia astrológica incluida en Meguilat ha-Megalé de Abraham bar Hiyya aparecen varios horóscopos históricos escritos en hebreo ${ }^{48}$. Pero Yehudá ben Barzilay declara abiertamente que está haciendo uso de una traducción anterior y hasta expresa una opinión muy crítica con respecto a su calidad ${ }^{49}$. Los fragmentos de Tafsîr Kitâb al-Mabâdi integrados por Yehudá ben Barzilay en el CSY son todo lo que resta en la actualidad de esta traducción. Además, el estilo arcaico y la nomenclatura astrológica hebrea de la traducción convierten a nuestro fragmento en un texto sui generis.

Después de haber declarado en el prólogo que el giro de la esfera celeste produce diversas configuraciones estelares, las posiciones de los planetas en los signos zodiacales son dadas para el mediodía de la susodicha fecha (§2). A continuación, basándose en estos datos astronómicos y en una especie de ejercicio teórico, la esfera celeste es inicialmente girada hacia atrás para indicar las posiciones de los planetas en la primera y segunda horas del día (§3). Luego, la esfera celeste es girada gradualmente hacia adelante cuatro veces en intervalos de $30^{\circ}$, que equivalen cada una de ellos a la longitud de un signo zodiacal. En cada uno de estos giros las posiciones de los planetas son dadas sucesivamente para la primera y segunda $(\S 3)$, tercera y cuarta $(\S 4)$, quinta y sexta $(\S 5)$, séptima y octava $(\$ 6)$, y finalmente novena y décima horas del día a partir del amanecer (\$7).

Aunque la fecha indicada en el fragmento no corresponda ni al nacimiento de ningún individuo ni a ningún suceso de carácter general para los cuales se quiera hacer alguna predicción astrológica concreta, ya en el prólogo leemos

46 Commentar, págs. 20, 22, 26, 34, 35, 37, 63, 92, 93, 131, 135, 155, 162, 166, 174, 177, 184, 209, 213, 221, 229, 237, 238, 239, 244, 254, 255, 260, 261, 268.

47 Commentar, págs. 64, 77, 89, 190, 193, 197.

48 Ver, inter alia, Sefer Megillat ha-Megalle von Abraham bar Chija, ed. A. Z. PozNANSKI, con introducción y notas de J. Y. GutTMan (Berlin 1924), págs. 119-212 et passim. Para un breve estudio de esos horóscopos, SElA, «Abraham Bar Hiyya’s Astrological Work and Thought», págs. 133-136.

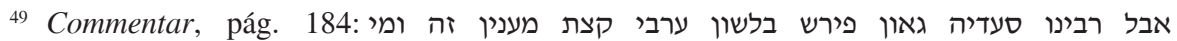
אבל רבי en la lengua árabe algo de este asunto, pero quien lo tradujo a la lengua santa no lo hizo con el debido esmero'). 
que «se forman configuraciones disímiles las unas de las otras, y de ellas derivan los juicios astrológicos» (\$1). Luego, los planetas son colocados en sus correspondientes casas horoscópicas ${ }^{50}(\$ \S 3-7)$ y se hace referencia explícita o implícita a sus aspectos $^{51}$ (\$§3-6) para establecer cuál de ellos es el planeta regente $^{52}(\$ 3, \S 5)$. Todo esto no deja duda de que el autor, además de utilizar tablas astronómicas para fijar las posiciones planetarias, hizo uso de la teoría astrológica horoscópica de origen griego.

La traducción hebrea que utilizó Yehudá ben Barzilay, además de confusa y extremadamente literal, revela un incipiente vocabulario astrológico hebreo. Veamos tres ejemplos de interés:

(a) Para traducir la expresión árabe aḥkâm al-nujûm, transmitida a la cultura latina como iudicia astrorum y otras locuciones afines (que denotan una serie de reglas o prescripciones astrológicas, formuladas con simpleza con el objetivo de pronosticar el destino particular o colectivo de la humanidad,) el traductor utilizó la palabra hebrea gezerot (גזירות) (גז). Curiosamente, Abraham bar Hiyya utilizó ese mismo término hebreo ${ }^{53}$ pero Abraham Ibn 'Ezra, influenciado por el hebreo bíblico, optó posteriormente por mišpațim (משפטים). ${ }^{54}$

(b) Para designar al planeta regente el traductor usó las expresiones singulares amiṣ we-ḥazaq (אמיץ וחזק, lit. 'valiente y poderoso') y ha-Hazaq ba-galgal (החזק בגלגל, lit. 'el poderoso en la esfera'), acerca de las cuales no he encontrado ni usos precedentes ni posteriores en la literatura hebrea.

(c) Para señalar el concepto de aspecto astrológico el traductor utilizó una variedad de palabras y expresiones. En primer lugar, mabaț (מבט) y otras expresiones afines $(\S 4, \S 8)$, que son traducciones del árabe nazar. No he podido ubicarla en la literatura hebrea anterior, pero esta palabra hebrea con esta acepción astrológica va a tener una gran difusión, comenzando con la obra astroló-

50 Las casas horoscópicas (griego topoi, árabe buyût, latín domicilia) son doce divisiones del zodíaco calculadas de acuerdo a alguna latitud u horizonte. Cada una de ellas indica una variedad de relaciones y experiencias humanas.

51 Los aspectos astrológicos son ciertas relaciones angulares que se dan especialmente entre los planetas, pero también entre signos zodiacales u otras entidades celestes: sextil $=60^{\circ}$; cuadratura $=90^{\circ}$; trino $=90^{\circ}$; oposición $=180^{\circ}$.

52 El planeta regente es el más poderoso en su influencia astrológica en determinada configuración horoscópica.

53 Bar Hiyya, Iggeret, págs. 27, 29, 30, 30, 31, 32, 33; Sefer Megillat ha-Megalle, págs. 112-115.

54 Sh. SElA, «El papel de Abraham Ibn Ezra en la divulgación de los ‘juicios’ de la astrología en la lengua hebrea y latina», Sef 59 (1999), págs. 159-194. 
gica de Bar Hiyya e Ibn 'Ezra, en la literatura hebrea posterior relacionada a la astrología ${ }^{55}$. En segundo lugar, el traductor hizo uso de metáforas perifrásticas desconocidas en la literatura hebrea anterior o posterior, como cuando los rayos de luz caen en algún lugar del horóscopo (\$3), para indicar la existencia de aspecto astrológico $(\$ 3, \S 5)$, o como cuando la luz se ausenta y se aleja o cuando planetas se hunden $(\$ 3, \S 5)$, para indicar la ausencia de aspecto astrológico.

\section{UNA MISCELÁNEA DE TEORÍAS ASTROLÓGICAS}

\section{Texto Hebreo}

מ = Ms. London, Montefiore Library 312, fols. 150a-150b (IMHM, JNUL, Jerusalem: F 05257)

ה = S. J. Halberstam, Commentar zum Sepher Jezira von R. Jehuda b. Barsilai aus Barcelona (Berlin 1885), págs. 247-248.

ב = Baraita di-Šemuel, ed. Natan 'Amram (Salónica 1861), reimpreso en Po'al haŠem (Bné Braq 1998), vol. I.

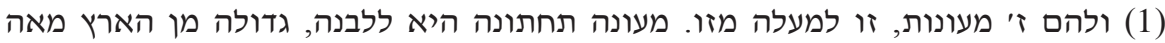

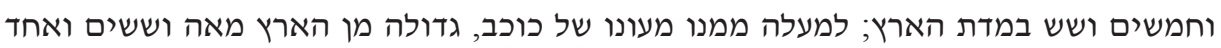

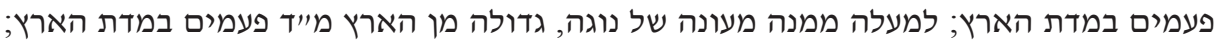

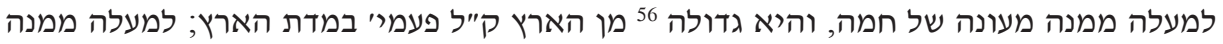

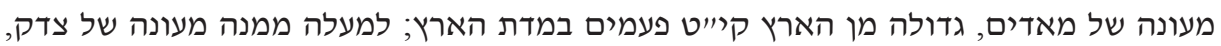

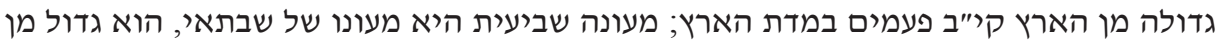
הארץ ר״ל מדו העמים במדת הארץ. (2) אמרתי מעונתם נאמר טביעתם: חמה אש; כוכב חורב; צדק רוח; נגה מטר; לבנה צונן; שבתי יותר ממנה; מאדים רותח.

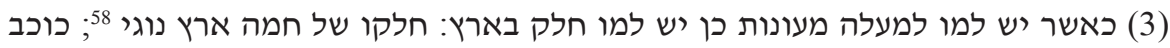

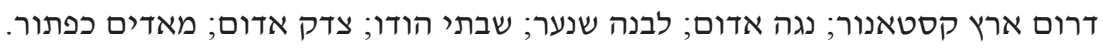

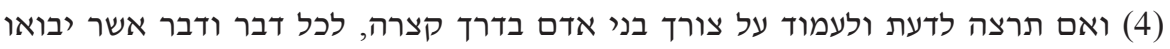
וישאלו ממך צורך דבר, ראה באיזה חלק של יום. כי אתה תרצה לחלק את היום לשמנה

55 Ver, inter alia, Abraham Ibn 'Ezra, Rešit Hokná, en R. LEvy and F. CANTERA, The Beginning of Wisdom. An Astrological Treatise by Abraham Ibn Ezra (Baltimore 1939), III, pág. XXXIX. Abraham bar Hiiyya, Sefer Megillat ha-Megalle, págs. 120, 122, 124, passim; GERSONIDES, Com. Levítico 8:34, 13:4; Com. Job 38:33-35.

56 גדולה]; מה בתוך גדולה; corregido según el contexto.

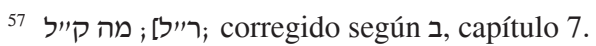

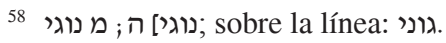




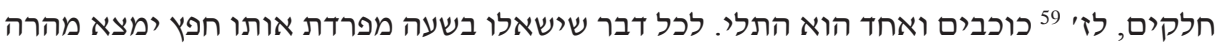

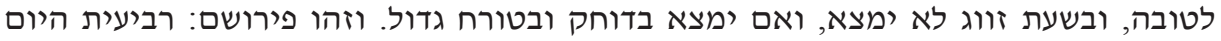

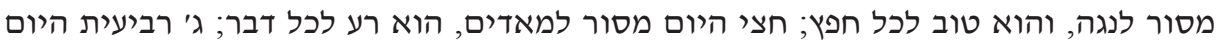

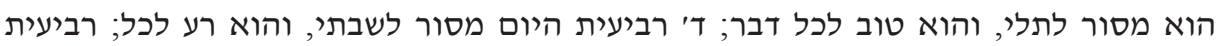

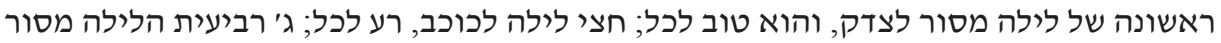

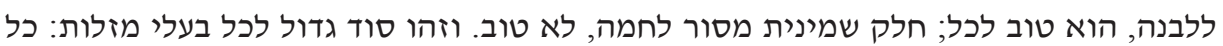

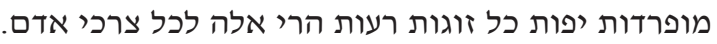

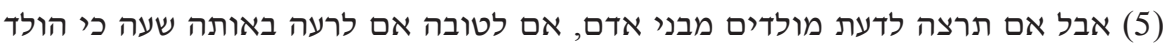

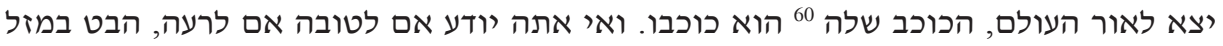

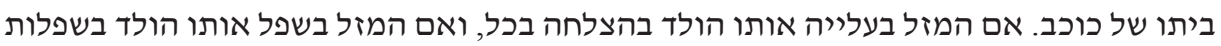

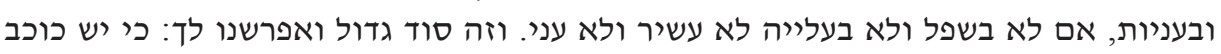

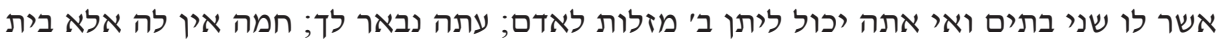

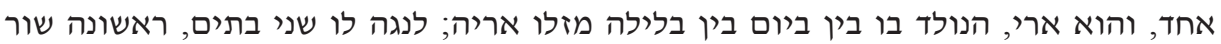

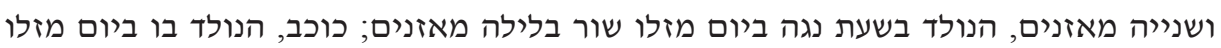

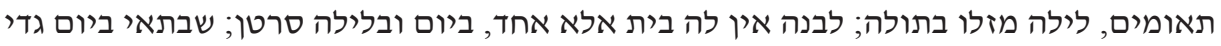

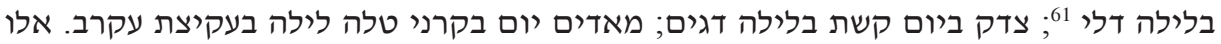

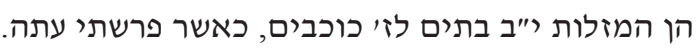

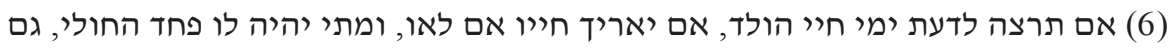

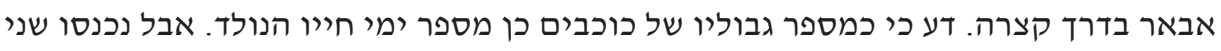

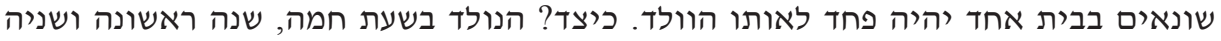

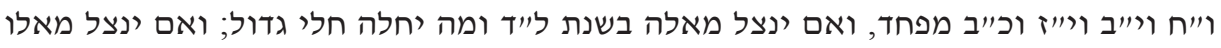

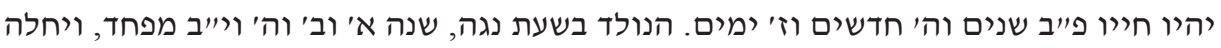

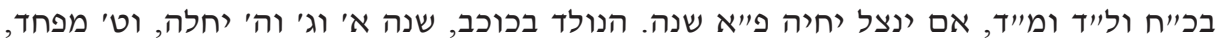

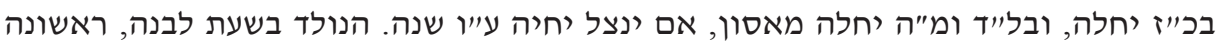

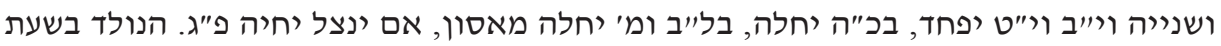

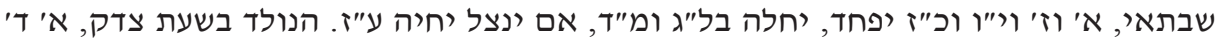

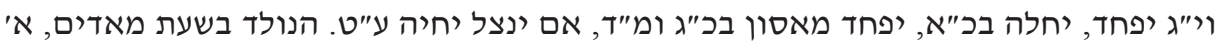

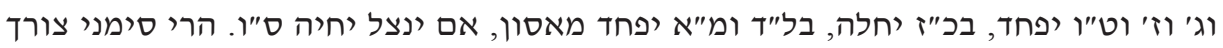

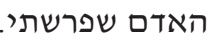

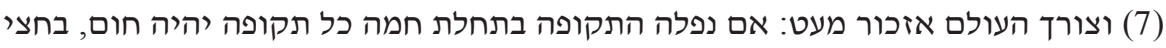

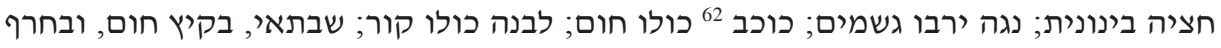

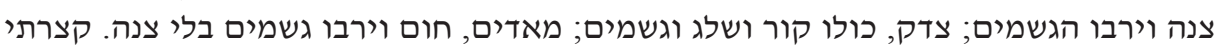

\footnotetext{
59 שלח; corregido según el contexto.

60 שלה]; corregido según el contexto.

61 דלי]; agregado según el contexto.

62 כוכב]; corregido según el contexto.
} 


\section{TRADUCCIÓN}

(1) Ellos tienen siete mansiones, una encima de la otra. La Luna tiene la mansión más baja, que es 156 veces mayor que el tamaño de la Tierra; arriba de ella la mansión de Mercurio, 161 veces mayor que el tamaño de la Tierra; sobre ella la mansión de Venus, 44 veces mayor que el tamaño de la Tierra; encima de ella la mansión del Sol, 130 veces mayor que el tamaño de la Tierra; sobre ella la mansión de Marte, 119 veces mayor que el tamaño de la Tierra; arriba de ella la mansión de Júpiter, 112 veces mayor que el tamaño de la Tierra; la séptima mansión es la de Saturno, 230 veces mayor que el tamaño de la Tierra.

(2) He presentado sus mansiones y ahora <presentaré> sus propiedades naturales: Sol fuego; Mercurio sequedad; Júpiter aire; Venus lluvia; Luna frío; Saturno más $<$ frío $>$ que ella; ${ }^{63}$ Marte hirviente.

(3) Así como tienen hacia lo alto sus mansiones, también les corresponden partes de la Tierra: el Sol tiene bajo su cargo la tierra de Nogi; Mercurio la parte sur de la tierra de Qastanur; Venus el sur de Edom; ${ }^{64}$ Luna Šin 'ar; ${ }^{65}$ Saturno India; Júpiter Edom; Marte Kaftor. ${ }^{66}$

(4) Si deseas saber y conocer brevemente las necesidades humanas con respecto a cualquier asunto, cuando vengan y te pregunten sobre alguna cuestión, fíjate en qué parte del día <estás $>$. Será bien que divididas el día en ocho partes, que corresponden a los siete planetas y al Dragón. Todo lo que pregunten en una hora impar se cumplirá con rapidez y fortuna, y en una hora par no se cumplirá o apenas se cumplirá y con grandes dificultades. Esta es la explicación que ellos le dan: el <primer> cuarto del día le corresponde a Venus, que es propicio para cualquier necesidad; la mitad del día le corresponde a Marte, que es funesto para todo; el tercer cuarto del día le corresponde al Dragón, que es propicio para todo; el cuarto cuarto del día le corresponde a Saturno, que es funesto para todo; el primer cuarto de la noche le corresponde a Júpiter, que es propicio para todo; la mitad de la noche le corresponde a Mercurio, que es funesto para todo; el tercer cuarto de la noche le corresponde a la Luna, que es propicia para todo; el $<$ último> octavo le corresponde al Sol, que es funesto. Este es un gran secreto conocido por todos los astrólogos: todos las <partes $>$ impares son propicias y las pares son funestas para toda empresa humana.

(5) Si deseas saber sobre las natividades de los seres humanos, si <alguna natividad> es propicia o funesta en la hora en que el niño ha nacido, $<$ debes saber $>$ que el planeta que está a cargo de la hora de nacimiento es el planeta que está a cargo del recién nacido.

63 O sea, más frío que la Luna.

64 O sea, la tierra de los cristianos.

65 O sea, Babilonia; ver Gé 10:10 et passim.

${ }^{66}$ O sea, la isla de Creta; ver Je 47:4 et passim. 
Si no sabes si es propicio o funesto, observa el signo zodiacal que corresponde a la casa de ese planeta ${ }^{67}$. Si el signo está ascendiendo el niño será muy afortunado, y si el signo zodiacal está descendiendo el niño será desdichado y pobre, y si no está ascendiendo ni descendiendo no será ni rico ni pobre. Te revelo <ahora > un gran secreto: hay planetas que tienen dos casas, pero tú no puedes atribuir a ninguna persona dos signos zodiacales. Ahora te explico <este asunto>: el Sol tiene sólo una casa, el signo de Leo, y si el niño nace en él, ${ }^{68}$ entonces Leo será su signo tanto de día como de noche; Venus tiene dos casas, la primera es Tauro y la segunda es Libra, el que nace en una hora que corresponde a Venus durante el día su signo es Tauro, y < si nace $>$ durante la noche < <u signo es $>$ Libra; si <el niño> nace en Mercurio durante el día su signo es Géminis, y si <nace> durante la noche su signo es Virgo; la Luna tiene sólo una casa, siendo Cáncer su signo durante el día o la noche; <el signo de > Saturno durante el día es Capricornio, y durante la noche Acuario; <el signo de> Júpiter durante el día es Sagitario, y durante la noche Piscis; <el signo de > Marte durante el día es en los cuernos de Aries, y durante la noche la picadura de Escorpio. Estos son los signos de las doce casas de los siete planetas, según acabo de explicar.

(6) Si deseas saber cuánto vivirá el recién nacido, si su vida será larga o corta, y cuándo tendrá miedo de caer enfermo, también explicaré brevemente <este asunto>. Debes saber que el número de los términos de los planetas ${ }^{69}$ es igual al número de años que vivirá el recién nacido. Pero si dos $<$ planetas $>$ maléficos entran en una casa, el recién nacido tendrá miedo $<$ de caer enfermo $>$. $<$ A continuación te explico $>$ cómo $<$ se calcula eso $>$. Quien nace en la hora del Sol, ${ }^{70}$ en los años $1^{\circ}, 2^{\circ}, 8^{\circ}, 12^{\circ}, 17^{\circ}$ y $22^{\circ}$ tendrá miedo <de caer enfermo>; si sobrevive caerá muy enfermo en el año $34^{\circ}$; si sobrevive, vivirá 82 años, 5 meses y 7 días. Quien nace en la hora de Venus, tendrá miedo $<$ de caer enfermo $>$ en los años $1^{\circ}$, $2^{\circ}, 5^{\circ}$ y $12^{\circ}$; caerá enfermo en los años $28^{\circ}, 34^{\circ}$ y $44^{\circ}$, y si sobrevive vivirá 81 años. Quien nace en la hora de Mercurio, caerá enfermo en los años $1^{\circ}, 3^{\circ}$ y $5^{\circ}$, tendrá miedo $<$ de caer enfermo $>$ en el año $9^{\circ}$, caerá enfermo en el año $27^{\circ}$, en los años $34^{\circ}$ y $45^{\circ}$ caerá enfermo por alguna calamidad, y si sobrevive, vivirá 76 años. Quien nace en la hora de la Luna, tendrá miedo <de caer enfermo $>$ en los años $1^{\circ}, 2^{\circ}, 12^{\circ}$ y $19^{\circ}$, caerá enfermo en el año $25^{\circ}$, en los años $32^{\circ}$ y $40^{\circ}$ caerá enfermo por alguna calamidad, y si sobrevive, vivirá 83 años. Quien nace en la hora de Saturno, tendrá miedo $<$ de caer enfermo $>$ en los años $1^{\circ}, 7^{\circ}, 16^{\circ}$ y $27^{\circ}$, caerá enfermo en los años $33^{\circ}$ y $44^{\circ}$, y si sobrevive, vivirá 77 años. Quien nace en la hora de Júpiter, tendrá miedo <de caer enfermo $>$ en los años $1^{\circ}, 4^{\circ}$ y $13^{\circ}$, caerá enfermo en el año $21^{\circ}$, en los años $23^{\circ}$ y $44^{\circ}$ caerá enfermo por alguna calamidad, y si sobrevive,

${ }^{67}$ Esta es una referencia a las casas planetarias, que son explicitadas a continuación.

68 O sea, si el niño nace en la hora que corresponde al Sol.

${ }^{69} \mathrm{O}$ sea, la suma total de los términos de los planetas en los doce signos zodiacales.

70 O sea, en una hora del día de la cual está a cargo el Sol. 
vivirá 79 años. Quien nace en la hora de Marte, tendrá miedo < de caer enfermo $>$ en los años $1^{\circ}, 3^{\circ}, 7^{\circ}$ y $15^{\circ}$, caerá enfermo en el año $27^{\circ}$, en los años $34^{\circ}$ y $41^{\circ}$ caerá enfermo por alguna calamidad, y si sobrevive, vivirá 66 años. Estas son las indicaciones sobre los asuntos individuales humanos que $<$ te $>$ he explicado.

(7) Mencionaré < ahora > brevemente asuntos mundanos. Si la tequfá ${ }^{71}$ llega al principio <de la hora $>$ del sol, habrá calor durante toda la tequfá, ${ }^{72}$ y si $<$ llega $>$ en la mitad $<$ de la hora del sol>, será moderado <el calor $>$; < si llega en la hora de $>$ Venus, ${ }^{73}$ abundarán las lluvias; <si llega en la hora de> Mercurio, <habrá> gran calor; <si llega en la hora de> la Luna, <habrá> gran frío; <si llega en la hora de> Saturno, <habrá> calor durante el verano, durante el invierno frío y abundarán las lluvias; <si llega en la hora de> Júpiter <habrá> gran frío con nieve y lluvias; <si llega en la hora de> Marte, $<$ habrá> calor y abundarán las lluvias sin frío. He sido breve.

\section{COMENTARIO}

Este texto exhibe una miscelánea de teorías cosmológicas y astrológicas. En primer lugar una cosmografía, luego trata las propiedades naturales de los planetas y sus relaciones con zonas geográficas, a continuación teorías relacionadas a las elecciones y natividades, y finalmente a la astrología meteorológica. Sin embargo, el común denominador de todas estas dispares teorías es la presentación de diversas propiedades astrológicas de los planetas. Examino a continuación separadamente cada uno de los pasajes.

\section{$\S 1$}

En el prólogo los siete planetas son ordenados según el método estándar -Luna, Mercurio, Venus, Sol, Marte, Júpiter, Saturno- adoptado por los adeptos a la escuela de Pitágoras y posteriormente por Claudio Tolomeo ${ }^{74}$. Curiosamente, los siete planetas son colocados en siete mansiones (מעונות), pero no queda claro si ese término es simplemente un sinónimo de esferas, o si corresponde a una cosmografía más tosca en la cual los planetas son instalados uno sobre el otro en planos horizontales, estando la Tierra en el nivel inferior.

71 El término hebreo tequfá (תקופה, Ex 34:22; 2 Cr 24:23; Sal 19:7) indica aquí el equinoccio vernal, o sea, el momento en que el Sol entra en el signo de Aries.

72 El término tequfá indica aquí el período que se extiende entre el momento en que el Sol entra en el signo de Aries y aquel en el que el Sol entra en el signo de Cáncer, o sea la estación de la primavera.

73 O sea, si la tequfá cae en una hora de la cual Venus es regente.

74 J. Evans, The History and Practice of Ancient Astronomy (New York-Oxford 1998), págs. 347-351. 
Las dimensiones de las mansiones con respecto a la Tierra son registradas, aunque no queda claro cuál es el patrón que sirve de unidad. Tampoco queda claro si estas comparaciones se refieren a la distancia de los planetas con respecto a la Tierra, o a alguna otra propiedad de las mansiones. Los números registrados en nuestro pasaje para representar la relación entre las mansiones y la Tierra son totalmente diferentes de los que podemos encontrar en sistemas cosmográficos antiguos que han llegado a nuestro conocimiento ${ }^{75}$.

Es posible ubicar idénticos datos a los indicados en nuestro texto en dos textos astronómicos y astrológicos hebreos, anteriores al siglo XII, que han llegado a nuestras manos con los nombres Baraita di-Šemuel (en adelante, BdS) y Baraita de-Mazzalot (en adelante, $B d M$ ). $B d S$, dividida en 9 capítulos que tratan temas relacionados al calendario, la astronomía y la astrología, y supuestamente idéntica a un texto del mismo nombre mencionado en fuentes post-talmúdicas, fue publicada en varias ocasiones a partir de $1861^{76}$. En un pasaje del quinto capítulo se registra el año 4536 AM, 776 de la era común, como la fecha de una observación astronómica, y esta sería la presunta fecha de composición de $B d S$, o por lo menos de una de sus partes ${ }^{77}$. Yehudá ben Barzilay conoció una obra designada con ese nombre, ya que al comienzo de un largo fragmento del $C S Y$ que puede ser ubicado en la edición impresa de $B d S$, él afirma explícitamente que pertenece a Baraita di-Š́muel ${ }^{78}$. Sin embargo, no es posible afirmar categóricamente que el pasaje de nuestro texto que puede ser ubicado en la edición impresa de $B d S$ haya pertenecido a esa obra. No es solo que Yehudá ben Barzilay no mencione explícitamente esta obra en nuestro texto, sino que también la segunda parte de $B d S$, que está principalmente consagrada a la astrología y en la cual puede ser ubicada la cita, está estrechamente relacionada a diversas partes de la ya mencionada BdM. BdM fue publicada en 1913 por A.

75 Para una comparación entre el volumen o el diámetro de la tierra y el volumen o el diámetro de las esferas de los planetas, ver, por ejemplo, B. R. GoldsteIn, «The Arabic Versions of Ptolemy's Hypotheses», Transactions of the American Philosophical Society [NS] 57, part 4 (1967), págs. 5-12. Para una comparación de los tonos musicales de las esferas de los planetas con respecto a la Tierra, de acuerdo a la Inscripción Canóbica atribuida a C. Tolomeo, ver N. M. SwerdLow, «Ptolemy’s Harmonics and the 'Tones of the Universe' in the Canobic Inscription», en Studies in the History of the Exact Sciences in Honour of David Pingree (Leiden-Boston 2004), págs. 165-170. Ver también Evans, The History and Practice of Ancient Astronomy, págs. 385-403.

76 BdS, ed. N. 'Amram (Salónica 1861); Baraita di-Šemuel ha-Qatan, comentada por L. LiPKIN (Pieterkov 1901). He utilizado aquí la reimpresión de esta edición en Po'al ha-Šem (Bné Braq 1998), vol. I.

$77 B d S$ V: בשנת ארבעה אלפים וחמש מאות ושלשים ושש שנה שוו חמה ולבנה En el año 4536 se igualaron la Luna y el Sol').

78 Véase infra nota 123. 
Wertheimer a partir de un manuscrito de la Guenizá de El Cairo ${ }^{79}$. Además de inventar el nombre especial de esta obra (o sea, baraita $^{80}$ de los signos zodiacales), Wertheimer la dividió en quince capítulos: los primeros seis dedicados a los signos zodiacales y los restantes a los planetas. Varios indicios señalan que importantes partes de $B d S$ y de $B d M$, a pesar de haber sido editadas como obras diferentes y con nombres diferentes, proceden de un mismo texto astrológico hebreo, hoy perdido, que circulaba en la Edad Media: los últimos nueve capítulos de $B d M$, dedicados a estudiar propiedades astrológicas y astronómicas de los planetas, son virtualmente idénticos o están estrechamente relacionados a los últimos cinco capítulos de $B d S^{81}$.

Tanto en el capítulo séptimo de $B d S$ como en el capítulo decimosegundo de $B d M$ ubicamos un pasaje que, después de una breve introducción en la cual los planetas son colocados en sus mansiones - de la misma manera que en el $C S Y$ - hace referencia a las dimensiones de las mansiones de los siete planetas con respecto a la Tierra. Una de la serie de números que exhibe este pasaje es idéntica a la serie de dimensiones de las mansiones con respecto a la Tierra según nuestro fragmento del $C S Y(\S 1)$. Para ilustrar la gran semejanza entre $B d S, B d M$ y $C S Y$, cito a continuación, como ejemplo del pasaje entero, la parte inicial del pasaje del capítulo séptimo de $B d S$, que incluye la introducción y las dimensiones de la Luna y Mercurio con respecto a la Tierra:

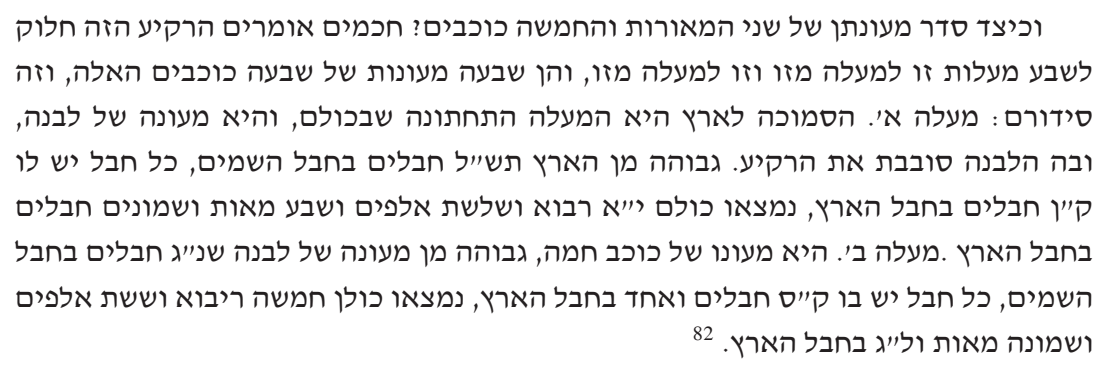

79 A. Wertheimer, Oșar midrašim kitve-yad [primera parte] (Jerusalem 1913), págs. 1-28. He utilizado aquí la reimpresión de esta edición en Po 'al ha-Šem (Bné Braq 1998), vol. I.

80 Con el nombre de baraita se suele indicar obras que son externas al corpus talmúdico.

81 Para un instructivo análisis de $B d M$ y una comparación de esta última obra con $B d S$, ver G. B. SARfAti, «Mabo le-Baraita de-Mazzalot», Bar Ilan 3 (1965), págs. 56-82. Ver también la reciente obra de R. LeICHT, Astrologumena Judaica (Tübingen 2006), págs. 82-89. Para un análisis de $B d S$, ver también E. BELler, «Ancient Jewish Mathematical Astronomy», Archive for History of Exact Sciences 38 (1988), págs. 61-66.

82 BdS VII; BdM XII. 
¿Cuál es el orden de las mansiones de las dos lumbreras y de los cinco planetas? Los sabios dicen que el firmamento esta dividido en siete mansiones, una encima de la otra, que son las siete mansiones de estas siete estrellas, y este es su orden. El primer grado es el más cercano a la Tierra y es el que está debajo de todos los demás, y es la mansión de la Luna, y en ella la Luna gira alrededor del firmamento. Es 730 hevel de los hevel celestes más alto que la Tierra, y cada hevel tiene 150 de los hevel de la Tierra, y todos juntos son 113880 hevel de la Tierra. El segundo grado es la mansión de Mercurio, es 353 hevel de los hevel celestes más alta que la mansión de la Luna, cada hevel tiene 161 de los hevel de la Tierra, y todos juntos son 56833 hevel de la Tierra ...

A modo de comparación, presento en la siguiente tabla todos los números correspondientes a las dimensiones de las mansiones de los siete planetas, según son registrados en el $C S Y$, por un lado, y en $B d S$ y $B d M$, por el otro:

\begin{tabular}{lcccc} 
CSY: & $\begin{array}{c}\text { BdS y BdM: } \\
\text { hevel de la } \\
\text { Pansiones con } \\
\text { respecto a la } \\
\text { medida de la } \\
\text { Tierra }\end{array}$ & $\begin{array}{c}\text { Tierra en cada } \\
\text { uno } \\
\text { de los hevel } \\
\text { celestes }\end{array}$ & $\begin{array}{c}\text { BdS y BdM: } \\
\text { hevel celestes }\end{array}$ & $\begin{array}{c}\text { BdS y } B d M: \\
\text { total de } \\
\text { hevel de la } \\
\text { Tierra }\end{array}$ \\
\hline Luna & 150 & 150 & 730 & 113.880 \\
\hline Mercurio & 161 & 161 & 333 & 56.833 \\
\hline Venus & 44 & 44 & 58 & 2.552 \\
\hline Sol & 130 & 130 & 318 & 41.340 \\
\hline Marte & 119 & 119 & 30 & 3.570 \\
\hline Júpiter & 112 & 112 & 612 & 68.544 \\
\hline Saturno & 230 & 230 & 510 & 117.300 \\
\hline
\end{tabular}

Dos puntos conectan estrechamente a nuestro pasaje $(\$ 1)$ con el pasaje correspondiente de $B d S$ y $B d M$.

a) En los tres textos se utiliza la palabra mansiones (מעונות) para indicar los grados o niveles de los planetas. Es esta una palabra de origen bíblico con algunas reminiscencias teológicas (Je 25:30, 21:13; $2 \mathrm{Cr}$ 36:15 et passim). Aparece luego en TB, Hag 12b, para indicar el quinto de los siete firmamentos ${ }^{83} \mathrm{y}$ con un idéntico significado aflora la misma palabra en $S Y$ (IV:16, VI:12). Más tarde es

83 Hag 12b: ריש לקיש אמר שבעה ואלו הן: וילון רקיע שחקים זבול מעון מכון ערבות. 
aplicada por Šabbetai Donnolo en su propio comentario al $S Y$ con exactamente el mismo significado que en $B d S$ y $B d M^{84}$. Después de haberla utilizado Yehudá ben Barzilay en el CSY, Abraham Ibn 'Ezra empleó frecuentemente la misma palabra con el significado de esferas planetarias en su comentario a Salmos (8:4, 19:2, 80:1, 96:6, 103:21) y en su segundo comentario a Génesis 1:14. ${ }^{85}$

b) Desconocemos el significado exacto otorgado a la palabra hevel como unidad de medida astronómica tanto en $B d S$ como en $B d M^{86}$. Sin embargo, las dimensiones de las mansiones de los siete planetas en comparación con el tamaño de la Tierra, según nos informa Yehudá ben Barzilay, son idénticas a la cantidad de hevel de la Tierra en cada uno de los hevel celestes según $B d S$ y $B d M$.

Estos dos puntos de contacto demuestran que Yehudá ben Barzilay, para redactar la configuración del cosmos en $\S 1$, hizo uso de $B d S$ o $B d M$, o de alguna otra obra perdida en la actualidad sobre la cual se basaron tanto $B d S$ como $B d M$. Dado que leemos en el $C S Y$ solo una parte de los datos que aparecen en $B d S$ y $B d M$, deducimos que Yehudá ben Barzilay realizó una depuración de esa fuente.

\section{$\S 2$}

En segundo lugar, nuestro texto presenta las «naturalezas» de los planetas. Para describir las propiedades naturales de los planetas, la astrología grecoárabe suele atribuir a cada uno de los planetas un par de cualidades entre los dos pares de propiedades contrarias que la física aristotélica asigna a cada uno de los cuatro elementos fundamentales del mundo sublunar (seco/húmedo, frío/caliente) ${ }^{87}$. Sin desviarse de estas convenciones, nuestro texto adopta

84 Il commento de Sabbetai Donnolo, pág. 58: ומהם נחקקו ונוצרו בעולם שבעה הכוכבים שצ"ם חנכ"ל ושבעה רקיעים להיות מעונותם של שבעה הכוכבים האלה.

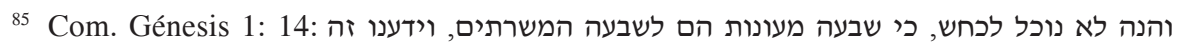

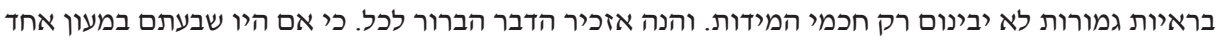

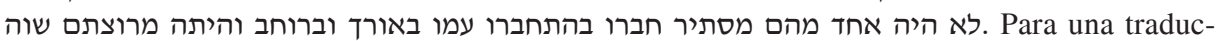
ción y explicación de este comentario, ver Sh. SELA, «La creación del mundo supralunar según Abraham ibn Ezra: un estudio comparativo de sus dos comentarios a Génesis», Sef 63 (2003), págs. 147-182.

86 Hevel (חבל) puede significar 'cuerda' o 'zona geográfica'. Fue utilizada para denotar cierta desconocida unidad de medida astronómica tanto en algunos midrašim (Midraš Zuta Kohelet, cap. A; Midraš Tehilim, cap. 19) como en la obra astronómica Șurat ha-areṣ de Abraham bar Hiyya (ed. S. Munster, Basel 1546, pág. 147).

87 Así, Saturno es considerado frío y seco como la tierra; Júpiter, caliente y húmedo como el aire; Marte, caliente y seco como el fuego; el Sol, caliente y seco como el fuego; Venus, frío y húmedo como el agua; Mercurio frío y seco como la tierra; la Luna fría y húmeda como el agua. Ver Ptolemy, Tetrabiblos, edited and translated by F. E. RobBIns (London 1980), I:4, págs. 35-37; Al-Qabîsî (Alcabituis), The Introduction to Astrology. Editions of the Arabic and Latin 
un enfoque especial. En algunos casos no señala el par de cualidades sino el elemento fundamental que las posee, o indica algún cuerpo físico dotado distintivamente de esas cualidades (Sol, fuego; Júpiter, aire; Venus, lluvia); en otros casos especifica solo una de las dos cualidades naturales y su intensidad (Mercurio, sequedad; Luna, frío; Saturno, más frío que la Luna; Marte, hirviente).

Muy idiosincrásica es la nomenclatura hebrea utilizada, y radicalmente diferente de la utilizada por otros autores hebreos posteriores, como Abraham bar Hiyya y Abraham ibn 'Ezra. Así, para describir a Mercurio se usa el vocablo Horeb (חורב), que puede significar frío pero también terral; para exhibir a Saturno se utiliza la palabra Șonen (צונן), que también puede significar frío, y para designar a Venus se usa el vocablo mațar (מטר), que significa lluvia. Esta terminología especial nos asiste ahora para descubrir la fuente de Yehudá ben Barzilay: todas estas idiosincrásicas palabras hebreas son utilizadas para caracterizar a los planetas, excepto Marte, en $B d S$, la misma fuente señalada con respecto al pasaje anterior ${ }^{88}$.

\section{$\S 3$}

A continuación nuestro texto pasa a asignar a cada uno de los planetas una zona geográfica, otra de las típicas propiedades de los planetas que aparecen habitualmente en introducciones medievales a la astrología ${ }^{89}$. Sin embargo, no hemos podido ubicar en la literatura astrológica previa al siglo XII nada semejante a lo que trae nuestro pasaje, tampoco en las ediciones impresas de $B d S$ o $B d M$. Una peculiaridad que nos sugiere que Yehudá ben Barzilay hizo uso de alguna fuente astrológica hebrea desconocida son los especiales nombres bíblicos asignados a las zonas geográficas: Edom (Gé 32:3 et passim), que indica

texts and an English translation, Ch. Burnett, K. Yamamoto, M. Yano (London-Turin 2004), II:1-36, págs. 63-83; Al-Bîrûnî, The Book of Instruction in the Elements of the Art of Astrology. R. RAMSAY Wright, ed. and trans. (London 1934), par. 396-401, pág. 240; Abû Ma'shar, The Abbreviation of the Introduction to Astrology, together with the Medieval Latin Translation of Adelard of Bath. Ch. Burnett, K. Yамамото, M. Yano, eds. and trans. (Leiden 1994), V:1-32, págs. 61-69; Abraham Ibn 'Ezra, Rešit Họkmá IV, págs. XLII-LI.

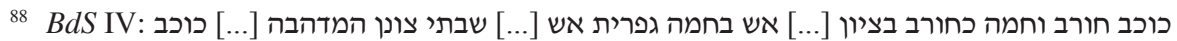
Mercurio seco y el Sol seco en Sión [...] fuego en el Sol, azufre fuego [...] Saturno frío opresión [...] Mercurio seco por medio de Mercurio de Jacob [...] Venus lluvia de Venus y lluvia, Júpiter el aire de equidad y justicia').

${ }^{89}$ Ptolemy, Tetrabiblos, II:3, págs. 133-161; Al-Qabîsî: The Introduction to Astrology, II:136, págs. 63-83; Al-Bîrûnî, The Book of Instruction in the Elements of the Art of Astrology, par. 407-408, pág. 242; Ibn 'Ezra, Rešit Hoknmá, IV, págs. xlii-li. 
comúnmente la tierra de los cristianos; Šin 'ar (Gé 10:10 et passim), que designa a Babilonia; y Kaftor (Je 47:4 et passim), que denota a Creta. Asimismo, el uso reiterado en nuestro pasaje del término especial mansiones, nos hace pensar que este pasaje, como los dos anteriores, bebió de la misma fuente, ahora perdida, que sirvió de base a las ediciones impresas de $B d S$ y $B d M$.

\section{$\S 4$}

El comienzo de este pasaje da la impresión de presentar un procedimiento relacionado a las doctrinas de interrogaciones o elecciones ${ }^{90}$. Pero la continuación deja claro que este pasaje se propone presentar las partes del día sobre las cuales rigen los planetas; o sea, como las demás partes de este texto, también nuestro pasaje está centrado en una de las propiedades astrológicas de los siete planetas. En este contexto, Yehudá ben Barzilay presenta varias teorías astrológicas, algunas de ellas rutinarias, pero otras desconocidas y sorprendentes:

a) El día es dividido en ocho partes, cuatro corresponden al tiempo de claridad, y las cuatro restantes al período de la noche. Es esta una manera insólita de dividir el día, utilizada en relojes de sol, pero, que yo sepa, ausente en la astrología greco-árabe.

b) Siete de estas ocho partes del día son asignadas a los siete planetas y concebidas alternativamente como propicias o funestas según la conocida teoría que califica a los planetas como benéficos, maléficos o neutrales. Así, Saturno y Marte son maléficos, Júpiter, Venus y la Luna son benéficos. Pero el Sol y Mercurio, que son habitualmente considerados como neutrales, son presentados en nuestro texto como maléficos ${ }^{91}$.

c) A los siete planetas se suma el Dragón, que es tratado como un objeto celeste de carácter benéfico. El Dragón está totalmente ausente del Tetrabiblos de Claudio Tolomeo, pero se hace rutinario presentarlo dividido en dos entiראש : ראש ;תנין/התלי וזנבו; árabe: ras wa dhanav al-tinnîn; latín: caput draconis et cauda), que corresponden a los dos nodos lunares— solamente a partir de la astrología

90 Interrogaciones (hebreo שאלות, griego eroteseis, árabe masâil, latín quaestiones) y elecciones (hebreo מבחרים, griego katarkhai, árabe ikhtiyârât, latín electiones) son dos ramos de la astrología greco-árabe destinados a guiar al astrólogo a responder cuestiones de tipo general o preguntas relacionadas con la elección del momento propicio para comenzar cualquier tipo de tareas.

91 Ptolemy, Tetrabiblos, I:5, pág. 39; Al-Qabîsî: The Introduction to Astrology, II:1-36, págs. 63-83; Al-Bîrûnî, The Book of Instruction, par. 382, págs. 232-233; Abû Ma'shar, Abbreviation, $\mathrm{V}: 1-32$, págs. 61-69. 
árabe ${ }^{92}$. Sin embargo, en nuestro texto el Dragón no es visto como dos entidades astrológicas diferentes, sino como un objeto celeste monolítico, y además es designado con el idiosincrásico nombre de teli (תלי) (תי) ${ }^{93}$. Esta palabra hebrea, encarada como un poderoso objeto monolítico, aparece claramente en el SY, donde leemos que «el Dragón (teli) está en el mundo como un rey en su trono» (תלי בעולם כמלך על כסאו). Como era de esperar, el Dragón emerge nuevamente en los primeros comentarios al SY. En su comentario inaugural, Sa'adyá Gaón inicia una tradición según la cual el Dragón, revestido con el carácter bipartito de los dos nodos lunares ya señalados, es designado con el término árabe jawzahar, o con la expresión bíblica naḥaš bariaḥ ('serpiente huidiza', Jb 26:13). ${ }^{94}$ Esta tradición es continuada por Dunaš Ibn Tamim ${ }^{95}$, por Šabbetai Donnolo en su Sefer Haknmoní ${ }^{96}$, por el propio Yehudá ben Barzilay en otra parte del CSY donde copia literalmente las explicaciones de Sa'adyá Gaón ${ }^{97}$, y más tarde tam-

92 Al-Qabîsî: The Introduction to Astrology, II:45-48, págs. 88-89; Abû Ma'shar al-Balhi (Albumasar), Kitâb al-madhal al-kabîr ila sinâ 'at ahkâm al-nujûm, Liber introductorii maioris as scientiam judiciorum astrorum. Edition critique par Richard LEMAY (Napoli 1996), VII:6, v, pág. 307; Abbreviation, 1994, IV:15, págs. 55-57; Ibn 'Ezra, Rešit Hokná V, págs. LII-LIII. Hay una breve mención de la cabeza y la cola al final del Pentateuco de Doroteo de Sidón (ca. 25-ca. 75), D. PIngree (ed.), Dorothei Sidonii Carmen Astrologicum, Interpretationem arabicam in linguam anglicam versam una cum Dorothei fragmentis et graecis et latinis (Leipzig 1976), V:43, pág. 322. Pero debe tenerse en cuenta que esta obra fue editada a partir de una traducción posterior al árabe y puede por lo tanto estar contaminada de interpolaciones posteriores.

93 Notamos también un significado parecido en otras partes del comentario de Yehudá ben

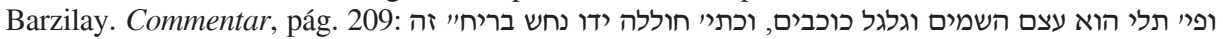
El El' התלי המנהיג את הגלגל ברוח. והגלגל והתלי אינם מדברים שאנו יכולים לתפשם כי לראותם בראיית העין Dragón significa el cielo propiamente dicho y la esfera de las estrellas, según estáescrito: «su mano atravesó la serpiente huidiza» [Jb 26:13]. El Dragón rige la esfera con el soplo. La esfera y el Dragón no son de aquellas cosas que uno pude captar con la vista de los ojos').

94 Kitâb al-Mabâdi, págs. 60-61.

95 VAJDA, Le Commentaire sur le Livre de la Création, págs. 135-136, 140.

96 Il commento de Sabbetai Donnolo, págs. 79-80.

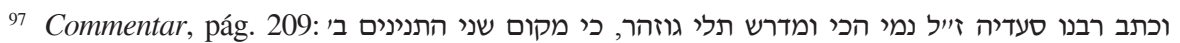

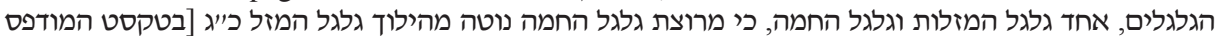

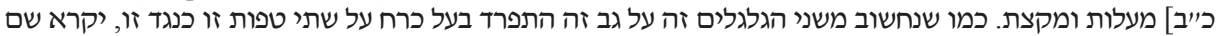

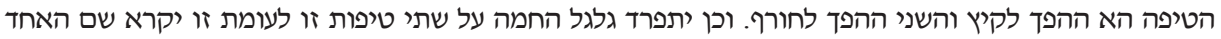

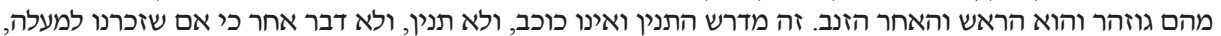

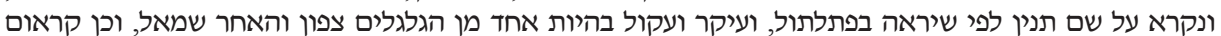
רכתוב באומרו חוללה ידו נחש בריח que el Dragón es Gozhar [ár.: al-jawzahar], ya que el lugar de los dos dragones es <la intersección de> dos círculos, el zodíaco y el círculo del sol, ya que el movimiento del círculo del sol está inclinado 23 grados y pico con respecto al movimiento del zodíaco. Imaginemos <la intersección de esos $>$ dos círculos, uno sobre otro, estos se separan necesariamente en dos puntos simétricos opuestos. Uno de ellos es designado opuesto al verano y el otro opuesto al invierno. También el círculo del Sol se separa en dos puntos opuestos, uno de ellos es designado Gozhar y es la cabeza, y el otro es la cola. Esta el la 
bién por Abraham Ibn 'Ezra ${ }^{98}$. Paralelamente, continuando la tradición iniciada por $S Y$, el Dragón también surge como una entidad cosmológica poderosa y monolítica, a la par de los siete planetas y dotada de influencia astrológica, en otra parte del Sefer Hakmoní de Šabbetai Donnolo ${ }^{99}$ y así también en $B d S{ }^{100}$. Esto sugiere que para la singular visión del Dragón de nuestro pasaje, Yehudá ben Barzilay hizo uso de fuentes hebreas desconocidas aunque emparentadas con las dos últimas obras.

d) Además de señalar la división del día en ocho partes, alternativamente propicias o funestas, nuestro texto menciona otra teoría astrológica que divide el día en horas (שעות) propicias o funestas según sean impares o pares. De acuerdo a la astrología árabe, las horas impares son masculinas y las pares son femeninas, de tal manera que los niños nacen en horas impares y las niñas en horas pares ${ }^{101}$. Sea como sea, con toda probabilidad, en este caso Yehudá ben Barzilay estuvo siguiendo el hilo de fuentes astrológicas judías basadas en TB Šabb 129b, donde se instruye explícitamente a quien desee practicar una sangría evitar las horas pares porque son funestas, especialmente si están regidas por Marte, el planeta que rige el derramamiento de sangre ${ }^{102}$. Es justamente por haber puesto en practica esta misma teoría astrológica para elegir la hora propicia del casamiento de un alumno, que Abraham bar Hiiyya entró en conflicto con algunos miembros de la comunidad judía de Barcelona, y fue por la misma razón que Bar Hiyya escri-

explicación del Dragón, y no es ni una estrella, ni una serpiente, ni ninguna otra cosa, sino solamente aquello que hemos explicado arriba, y es designado con el nombre de «serpiente» porque aparece retorciéndose, y el principio de su torsión reside en que uno de los círculos se mueve hacia el norte y el otro hacia el sur, y así fue designado por las Escrituras: «su mano atravesó la serpiente huidiza» [Jb 26:13]').

98 Ver comentario a Jb 26:13, en M. Gómez ArAnda, El comentario de Abraham ibn Ezra al libro de Job. Edición crítica, traducción y estudio introductorio (Madrid 2004), págs. 59-50*, 195; B. R. Goldstein (ed.), Ibn al-Muthannâ's Commentary on the Astronomical Tables of alKhwârizmî. Two Hebrew versions, edited and translated with an astronomical commentary (New Haven-London 1967), págs. 296, 346; Sh. SEla, Abraham Ibn Ezra and the Rise of Medieval Hebrew Science (Leiden 2003), págs. 124-126.

99 Il commento de Sabbetai Donnolo, pág. 80.

100 BdS I, IV.

101 Ibn 'Ezra nos informa que de acuerdo a Ya'qub al-Kindî y Mâshâ'allâh, los niños nacen siempre en horas impares y las niñas en horas pares (Sefer ha-mivîarim, primera versión, München, Bayerische Staatsbibliotheck, Cod. Hebr. 202, fols. 111b, 114a; segunda versión de Sefer haTe 'amim, Abraham Ibn 'Ezra, the Book of Reasons. A Parallel Hebrew-English Critical Edition of the Two Versions of the Text. Edited, translated and annotated by Shelomo SELA (Leiden-Boston 2007), §6.1:1, págs. 234-235. Esto está probablemente relacionado con la intención de elegir horas propicias para engendrar hijos de sexo masculino, ya que Al-Bîrûnî y Al-Qabîsî nos informan que las horas impares son masculinas y las pares son femeninas (Al-Bîrûnî, The Book of Instruction, par. 390, pág. 238; Al-Qabîsî: The Introduction to Astrology, II:50, pág. 89).

102 The Babylonian Talmud, transl. I. EPSTEIn (London 1936), págs. 645-646. 
bió la conocida epístola en defensa de la astrología a Yehudá ben Barzilay. En esta epístola escribe Bar Hiyya que «es sabido por los sabios de la astrología que las horas pares no son propicias para comenzar ninguna tarea, y especialmente si están regidas por algún planeta maléfico» ${ }^{103}$. Curiosamente, también Yehudá ben Barzilay, al final de nuestro pasaje, nos informa que esta teoría es un «gran secreto conocido por todos los astrólogos».

\section{$\S 5$}

A continuación nuestro texto pasa a tratar varias teorías relacionadas con la doctrina de natividades, especializada en estudiar el destino individual de los seres humanos por medio de un análisis de la configuración celeste en el momento de nacimiento. El procedimiento astrológico mencionado en nuestro pasaje es sumamente tosco y está dividido en tres etapas principales ${ }^{104}$. Aunque en el prólogo se hace uso del término hebreo moladim (מולדים), natividades, y a pesar de que se hace referencia a la posición de los planetas y los signos zodiacales en el momento del nacimiento, remota es la relación entre los contenidos de este pasaje y la astrología horoscópica greco-árabe propiamente dicha, tal cual es presentado en el primer texto presentado más arriba. Sin embargo, el hecho que la atribución del destino personal al planeta regente de la hora de nacimiento es mencionada explícitamente en TB Šabb 156a, nos sugiere la posibilidad que Yehudá ben Barzilay ha utilizado alguna fuente hebrea desconocida ${ }^{105}$. Además, los planetas y sus respectivas casas planetarias, cuya enu-

103 Bar Hiyya, Iggeret, pág. 25.

104 a) Se averigua cuál es el planeta que está a cargo de la hora de nacimiento. Implícitamente se invoca aquí la bien conocida teoría que designa sucesivamente a los planetas como regentes de las 12 horas del día y las 12 horas de la noche de cada uno de los siete días de la semana. Ver Al-Bîrûnî, The Book of Instruction, par. 390, págs. 127-238; Al-Qabîsî, The Introduction to Astrology, II:50, pág. 89. A continuación b) se deduce cuál es la casa planetaria de ese planeta utilizando una conocida tabla de correspondencias entre planetas y signos zodiacales. Yehudá ben Barzilay agrega que debe procederse de esta manera cuando de la etapa anterior no queda claro «si esto es propicio o funesto». Esta condición es curiosa, ya que se ha visto más arriba que los planetas mismos son clasificados de propicios o funestos $(\$ 4)$. Pero posiblemente esta falta de claridad se debe a la posibilidad que el planeta regente sea uno de los planetas neutrales. Finalmente, c) después de haber averiguado el signo del zodiaco que es considerado como casa planetaria del planeta regente de la hora de nacimiento, el destino personal se fija de acuerdo a la situación del signo del zodiaco en el momento del nacimiento: propicio si el signo asciende, funesto si el signo desciende, incierto si está estacionario.

105 The Babylonian Talmud, transl. EpsteIn, pág. 799: «Not the constellation of the day but that of the hour is the determining influence. He who is born under the constellation of the Sun will be a distinguished man [...] He who is born under Venus will be wealthy and unchaste [...] He who is born under Mercury will be of retentive memory and wise [...] He who is born under the Moon will be a man to suffer evil [...] He who will be born under Saturn will be a man whose plans will be frustrated. He who is born under Jupiter will be a right-doing man [...] He who is born under Mars will be a shedder of blood». 
meración ocupa una buena parte de nuestro pasaje, son estudiados en detalle en $B d S$ y $B d M^{106}$. Finalmente, la terminología técnica hebrea de este pasaje — términos como מולדים, 'natividades', o ביתו של כוכב, 'casa planetaria'— sugiere que Yehudá ben Barzilay se basó en un texto hebreo anterior.

\section{$\S 6$}

Este pasaje del $C S Y$ — que se ocupa de otro aspecto fundamental de la doctrina de natividades: la predicción de la duración de la vida del recién nacido- es en gran parte idéntico y en otras extremadamente similar a un fragmento que puede ser ubicado en $B d M$, según veremos a continuación. A pesar de que ese fragmento de $B d M$ no aparece en la edición impresa de $B d S$, la estructura y ciertas particularidades comunes de $B d S$ y $B d M$ permiten deducir con toda seguridad que ese fragmento formaba parte del texto astrológico que les sirvió de base. Este fragmento se conservó en la edición impresa de $B d M$ pero se perdió en algún punto de la cadena de transmisión de la cual resultó la edición impresa de $B d S{ }^{107}$. Transcribo a continuación el fragmento que puede ser ubicado en $B d M$ acompañado de su traducción:

וכל יגיעה הזו למה, אלא ללמד שכשם שהם שמחים בבתיהן כך הם שמחים בגבולן, וליתן

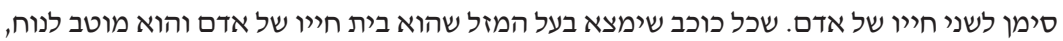

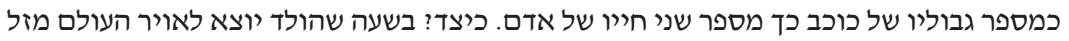

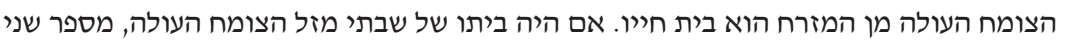

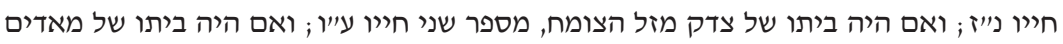

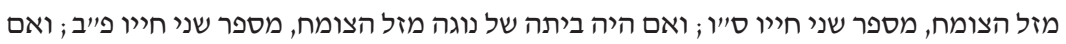

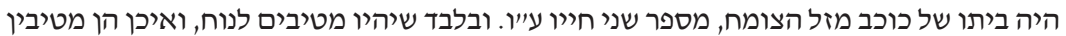

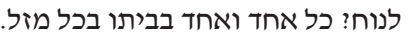

Todo este esfuerzo no fue sino para enseñar que así como $<$ los planetas $>$ se regocijan en sus casas, también se regocijan en sus términos, y para indicar la duración de la vida del ser humano. Todo planeta, si es regente del signo zodiacal que es la casa vital del hombre ${ }^{108}$ cuando <ese planeta> reside en un buen

$106 B d S$ V; BdM IX.

107 Tanto en $B d S$ como en $B d M$, la parte astrológica dedicada a los planetas, que se extiende a varios capítulos, está encabezada por un preámbulo casi idéntico que sirve en los dos textos a la manera de un índice general. Allí el autor declara de antemano cuáles son las propiedades de los planetas que tratará en los siguientes capítulos. Este preámbulo incluye, tanto en $B d S$ como en $B d M$, el tratamiento de los términos planetarios. Pero el capítulo dedicado a los términos está totalmente ausente del texto impreso de $B d S$, aunque los demás temas (luz, casa planetaria, marcha, «mansiones», exaltaciones y depresiones) aparecen en forma similar tanto en $B d S$ como en $B d M$.

108 O sea, la casa horoscópica que indica la vida del recién nacido, que es equivalente a la primera casa horoscópica que comienza en el grado ascendente. 
lugar ${ }^{109}$, la suma de sus términos equivale al número de años de la vida del hombre ${ }^{110}$. ¿Cómo? En la hora que el bebé sale al aire del mundo, el signo zodiacal que asciende en el oriente es la casa de su vida. Si el signo ascendiente es la casa $<$ planetaria $>$ de Saturno, el número de sus años será 57; si el signo ascendiente es la casa de Júpiter, el número de sus años será 76; si el signo ascendiente es la casa de Marte, el número de sus años será 66; si el signo ascendiente es la casa de Venus, el número de sus años será 82; si el signo ascendiente es la casa de Mercurio, el número de sus años será 76. Y esto $<$ se cumple > a condición que residan en una buena posición; ¿dónde es esa buena posición? cada uno de ellos en su casa $<$ planetaria $>$ en el correspondiente signo zodiacal.

Tanto en nuestro pasaje como en el fragmento de $B d M$, los cálculos destinados a averiguar la suma total de años de vida están basados en una teoría explícitamente formulada en el Tetrabiblos de C. Tolomeo ${ }^{111}$. Se hace referencia aquí a los términos (hebreo גבולים, griego oria, árabe hudûd, latín fines), o sea, divisiones desiguales que son asignadas a los planetas, excepto el Sol y la Luna, en cada uno de los doce signos zodiacales. BdM nos asiste ahora para revelar cómo se establece la identidad del planeta cuyo términos son sumados, un dato que Yehudá ben Barzilay dejó sin explicar: ese planeta es el regente del signo ascendiente en el horóscopo natalicio. Los números informados en las dos fuentes son casi idénticos, y suponemos que la única diferencia (en el caso de Venus) se debe al error de un copista durante la cadena de transmisión. Es notable que tanto en el caso de Saturno como en el de Júpiter, $B d M$ y Yehudá ben Barzilay nos hayan transmitido números erróneos que no corresponden a la suma total de los términos de esos dos planetas. Esto es sorprendente porque en $B d M$ el fragmento arriba citado es presentado al final de un capítulo dedicado al tema de los términos planetarios, y, justamente antes de presentar la mencionada teoría, $B d M$ exhibe las sumas totales de los términos de Saturno, Júpiter, Marte, Venus y Mercurio, que divergen notablemente en el caso de Saturno y Júpiter ${ }^{112}$.

109 O sea, según es explicado al final del fragmento, el planeta «reside en un buen lugar»si el signo zodiacal en el cual se encuentra es idéntico a una de sus casas planetarias. Para las casas planetarias, ver supra $§ 5$.

110 O sea, del recién nacido.

111 Ptolemy, Tetrabiblos, I:20, pág. 93: «for the number derived for each planet from the addition of its terms in all the signs, in accordance with which they say the planets assign years of life». Cf. A. Bouché-LeclercQ, L’astrologie grecque (Paris 1899), pág. 408.

112 Desde la Antigüedad se inventaron diversos métodos para medir los términos de los planetas, un tema que ha sido objeto de controversias entre diversas corrientes astrológicas. Claudio Tolomeo, por ejemplo, menciona el método de los egipcios, el de los caldeos, y un tercer método que él mismo halló en un antiguo y deteriorado manuscrito. Ptolemy, Tetrabiblos, I:2021, págs. 91-107. El método adoptado por $B d M$, y por consiguiente también por Yehudá ben Barzilay, es el que C. Ptolomeo atribuye a los astrólogos egipcios. Presento a continuación la suma total de los términos de los siete planetas según BdM: Saturno 57, Júpiter 76, Marte 66, Venus 82, Mercurio 76. BdM XIII. 
Sin embargo, existen dos notables discrepancias entre Yehudá ben Barzilay y $B d M$ : a) en conformidad con la teoría formulada por C. Tolomeo, $B d M$ presenta solo a los cinco planetas que poseen términos (el Sol y la Luna no tienen términos), y lo hace según el orden estándar de las esferas (Saturno, Júpiter, Marte, Venus, Mercurio). Pero Yehudá ben Barzilay exhibe a todos los planetas, también al Sol y la Luna que no tienen términos, y lo hace en un orden totalmente diferente: primero el Sol, Venus, Mercurio y la Luna; luego Saturno, Júpiter y Marte. Este orden sui generis es el mencionado tanto en $B d M$, en un preámbulo que encabeza los varios capítulos que estudian las diversas propiedades astrológicas de los planetas, y en $B d S$, en una sección donde se averigua el planeta regente de las estaciones del año ${ }^{113}$. Y b) $B d M$ menciona solamente los años de la duración de la vida que corresponden a la suma de los términos de los cinco planetas que poseen términos. Pero Yehudá ben Barzilay, además de presentar los años de la duración de la vida que corresponden a los siete planetas, también al Sol y la Luna que no tienen términos, exhibe también en ese mismo contexto una serie de números relacionados con los años en que el recién nacido «tendrá miedo de caer enfermo», «caerá enfermo» o «caerá enfermo por alguna calamidad». Estas predicciones son misteriosamente atribuidas a la posibilidad que dos maléficos (posiblemente Saturno y Marte) entren en una casa (posiblemente en Capricornio y Acuario, o Escorpio y Aries, que son las casas planetarias de Saturno y Marte).

El último pasaje trata la astrología meteorológica, parte integral de la macro-astrología o astrología universal. La teoría mencionada en este pasaje pretende realizar predicciones meteorológicas basándose en las propiedades astrológicas del planeta que es regente de la hora en la cual ocurre la tequfá, o sea, el equinoccio vernal. Es de interés señalar que los planetas en $\$ 7$ no son presentados según el orden estándar de las esferas sino comenzando desde el Sol, o sea, en el mismo orden sui generis en que aparecen en §6. Teorías de este tipo, que yo sepa, son anómalas en la astrología meteorológica greco-árabe. Pero, según veremos a continuación, una serie de pistas que pueden ser seguidas desde el Talmud de Babilonia, durante el medievo, y hasta el siglo XII sugieren que Yehudá ben Barzilay estuvo haciendo aquí uso de un texto hebreo hoy perdido.

En TB 'Erub 51a se menciona explícitamente a un sabio con el nombre de Šemuel que pregona los detalles de una teoría muy similar a la mencionada por Yehudá ben Barzilay en $\$ 7^{114}$. Un capítulo entero de $B d S$, escrito en un estilo oracu-

$113 B d M$ VII, $B d S$ V.

114 TB, 'Erub 51a: ואמר שמואל אין לך תקופת ניסן שנופלת בצדק שאינה משברת את האילנות ואין

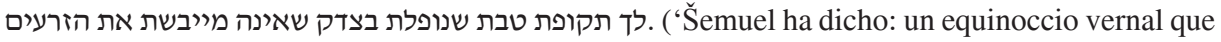


lar muy difícil de descifrar, hace explícita referencia de esta misma teoría dando varios ejemplos que, sin embargo, aparentan ser diferentes de los detalles que aparecen en $\$ 7^{115}$. Más aun, en otro pasaje del capítulo siguiente de $B d S$, la misma teoría es otra vez brevemente mencionada, pero esta vez los planetas involucrados son registrados en exactamente el mismo orden sui generis en que son mencionados en $\$ 7^{116}$. Asimismo, Abraham ibn 'Ezra y Abraham bar Hiyya, cada uno de ellos en su propio Sefer ha-'Ibbur ('Libro de la intercalación'), nos informan sobre una tradición judía antigua según la cual el conocimiento exacto del momento de la tequfá era guardado en secreto por que permitiría a astrólogos inescrupulosos conocer todo lo que acontece en la tierra ${ }^{117}$. Todos estos indicios nos sugieren que $\S 7$, análogamente a los otros componentes de la miscelánea astrológica que estamos analizando, está basado en un texto astrológico hebreo antiguo del cual derivaron posteriormente los textos que conocemos ahora como las ediciones impresas de $B d S$ y de $B d M$.

\section{CONCLUSIÓN}

El análisis de los dos textos conservados en el CSY estudiados en este artículo revela un caso especial y hasta este momento desconocido de recepción de fuentes astrológicas por intelectuales judíos en la península Ibérica. En claro contraste con Bar Hiyya e Ibn 'Ezra, que encarnan una corriente renovadora orientada a verter al hebreo diversos aspectos de la astrología y la ciencia árabe, Yehudá ben Barzilay representa una modalidad conservadora inclinada a la utilización de fuentes astrológicas y científicas de autores exclusivamente judíos. El examen del primer texto, aunque fuertemente influenciado por la astrología horoscópica greco-árabe, revela el uso de una traducción al hebreo, hoy perdida, de un pasaje escrito originalmente en árabe del comentario al $S Y$ de Sa'adyá Gaón. El estudio de los diversos com-

cae en Júpiter seguramente causará que los árboles sean derribados, y si un equinoccio estival cae en Júpiter, seguramente causará que las semillas se sequen').

115 BdS IV.

116 BdS V: הרוצה לידע איזה מזל משמש בתקופה, מן חנכ«ל שצ«ם, יחשוב כוכב התקופה שעומד בה. ('Quien quiera saber el planeta que rige la tequfá, entre el Sol, Venus, Mercurio, Luna, Saturno, Júpiter y Marte, deberá calcular cuál es el planeta que rige 'la hora en que cae la tequfá").

117 Ibn 'Ezra, Sefer ha-'Ibbur, ed. S. Z. H. Halberstam (Lyck 1874), pág. 6b; Bar Hiyya, Sefer ha-'Ibbur, ed. T. FILIPOVsKy (London 1851), pág. 94. Estos pasajes se refieren al método de cálculo del equinoccio vernal elaborado por Rav Adda (siglos III y IV), que era considerado más exacto que el método elaborado por Mar Šemuel, un sabio talmúdico que era designado como yarhinaha, el astrónomo, y fue posiblemente guiado por el calendario romano juliano. Para una traducción inglesa y un análisis de estos dos pasajes, ver Sh. SELA, «The Fuzzy Borders between Astronomy and Astrology as Reflected in the Thought and Work of Three Twelfth-Century Jewish Intellectuals», Aleph 1 (2001), págs. 76-80. 
ponentes del segundo texto revela que en este caso Yehudá, ben Barzilay utilizó un texto astrológico hebreo, hoy perdido, que posteriormente sirvió de base a los manuscritos de los cuales fueron editadas las versiones impresas modernas de $B d S$ y $B d M$. Este texto hebreo recoge tradiciones astrológicas de origen helenístico pero también teorías que son ajenas en algunos casos a la astrología greco-árabe y que indican un origen talmúdico.

No nos debe sorprender la posibilidad de que durante el siglo XII hayan circulado en la península Ibérica textos astrológicos hebreos desconocidos en la actualidad. Abraham bar Hiyya, en su epístola en defensa de la astrología, se refiere explícitamente a ciertas baraitot en las que los sabios de Israel expresaron sus opiniones con respecto a la astrología ${ }^{118}$. En su Sefer ha- 'Ibbur, Bar Hiyya menciona explícitamente tres baraitot con contenidos científicos que podrían ajustarse a esta categoría ${ }^{119}$. También Abraham Ibn 'Ezra conoció algún texto astrológico de este tipo, como se desprende del uso frecuente de la palabra mansiones (מעונות) en sus comentarios bíblicos ${ }^{120}$. Por otra parte, Yehudá ha-Leví en la cuarta parte del Cuzarí nos informa sobre una obra que él titula Los capítulos de Rabbi Eli' ezer y que trata diversos tópicos de la astrología: las medidas de la tierra y de las esferas, los signos de zodíaco, las propiedades naturales de los planetas, las casas planetarias, su buena y mala fortuna, sus términos, sus ascensiones y descensos, sus exaltaciones y detrimentos, y la duración de sus movimientos ${ }^{121}$. Pirqé de-Rabbi Eli' ezer es el nombre hebreo de la obra a la cual se estaba refiriendo Yehudá ha-Leví. Sin embargo, en vano buscaremos en la edición moderna de esta obra la sección dedicada a la astrología a la cual se refería este autor ${ }^{122}$. Pero los diversos temas astrológicos que según Ha-Leví, trataba esa sección perdida de Pirqé de-Rabbi Eli'ezer son análogos a los

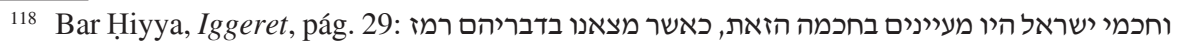

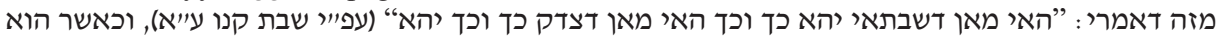
"Los sabios de Israel estudiaron esta ciencia [la astrología], según hemos hallado indicio de ello en lo escrito: «quien nace bajo el signo de Saturno será de esta manera, y quien nace bajo el signo de Júpiter será de la otra» [TB Šabb 165a], y según esta afirmaciones han sido interpretadas en las baraitot que fueron escritos con su nombre [o sea, con el nombre de esos sabios]').

119 Estas obras son: $B d S$ de la cual Bar Hiyya cita un fragmento que puede ser ubicado en la edición impresa; Baraita de-Rabbi Eli ezer ben Horcanos, una obra que es muy posiblemente idéntica a Pirqé de-Rabbi Eli'ezer; y Baraita de-Rav Adda bar Ahavá, una obra perdida en la actualidad. Bar Hiyya, Sefer ha-'Ibbur, págs. 36 y 87.

120 Ver supra nota 85.

121 Ha-Leví, Sefer ha-Kuzarí, IV:29, pág. 191; una traducción inglesa y un análisis de ese pasaje se encuentran en GoldSTEIN, «Astronomy and the Jewish Community», págs. 55-57.

122 Pirqé de-Rabbi Eli'ezer (Warsaw 1852). He utilizado aquí la reimpresión de esta edición en Po'al ha-Šem (Bné Braq 1998), vol. I. 
temas astrológicos que tratan $B d S$ y $B d M$. ¿Es posible que la fuente astrológica hebrea que utilizara Yehudá ben Barzilay en el CSY, una de las baraitot mencionadas por Bar Hiyya, el texto del cual Ibn 'Ezra extrajo la palabra mansiones, la obra con contenidos astrológicos que conoció Yehudá ha-Leví y la fuente astrológica hebrea perdida de la cual derivan las ediciones modernas de $B d S$ y $B d M$, sean la misma obra? En el estado actual de la investigación todavía sería prematuro dar una respuesta categórica positiva, aunque los datos señalados apuntan en esa dirección.

Un examen preliminar de las otras partes del CSY donde fueron introducidos contenidos científicos revela un cuadro similar: Yehudá ben Barzilay optó por utilizar exclusivamente fuentes científicas de autores judíos, especialmente textos escritos en árabe traducidos más tarde al hebreo o textos originales hebreos. El estudio de estos interesantes textos excede los límites de este artículo. Sin embargo, en calidad de anticipo, es posible afirmar que en el CSY fueron utilizadas las siguientes fuentes de carácter científico: a) un extenso pasaje astronómico corresponde palabra por palabra a casi todo el primer capítulo de la edición impresa de $B d S^{123}$; b) el Tafsîr Kitâb al-Mabâdi de Sa'adyá Gaón no solo para la astrología sino también para la astronomía ${ }^{124}$; c) el comentario a $S Y$ de Dunaš Ibn Tamin para las matemáticas, la astronomía, la astrología, la medicina, la biología y la cosmología ${ }^{125}$; d) escritos de Hai Gaón (939-1038) también para la cosmología ${ }^{126}$.

Recibido: 29/03/2007

Aceptado: 05/10/2007

123 BdS I: עגלה בצפון ועקרב בדרום. זורח עיגול כלפי דרום ושוקע עיגול כלפי צפון [...] שמש וירח קדרו,

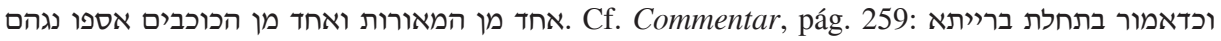

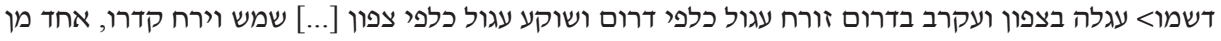

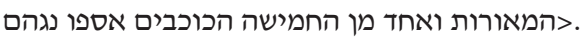

124 Véase, inter alia, Commentar, págs. 127-128, cf. Kitâb al-Mabâdi, pág. 45; Commentar, pág. 129, cf. Kitâb al-Mabâdi, pág. 39.

125 Ver, inter alia, Commentar, pág. 265, cf. Le Commentaire de Dûnaš ben Tâmîm pág. 144; Commentar, pág. 151, cf. Le Commentaire de Dûnaš ben Tâmîm, págs. 65-66; Commentar, pág. 144, cf. Le Commentaire de Dûnaš ben Tâmîm, págs. 53-54; Commentar, pág. 264, cf. Le Commentaire de Dûnaš ben Tâmîm págs. 137-138.

126 Commentar, pág. 149. 